\title{
Article
}

\section{Strain, sex, and time dependent antidepressant-like effects of cannabidiol}

\author{
Gabriela P. Silote 1,2, Michelle C. Gatto ${ }^{1}$, Amanda Eskelund ${ }^{2}$, Francisco S. Guimarães ${ }^{3,4}$, Gregers Wegener ${ }^{2}$ and \\ Sâmia R. L. Joca ${ }^{1,5, *}$
}

1 Department of Biomolecular Sciences, School of Pharmaceutical Sciences of Ribeirão Preto (FCFRP), University of São Paulo USP), Brazil; gabrielasilote@gmail.com (G.P.S.); michelle.gatto@hotmail.com (M.C.G.); sjoca@biomed.au.dk (S.R.L.J).

2 Translational Neuropsychiatry Unit (TNU), Department of Clinical Medicine, Aarhus University, Aarhus, Denmark; ares@clin.au.dk (A.E.); wegener@clin.au.dk (G.W.).

3 Department of Pharmacology, School of Medicine of Ribeirão Preto, University of São Paulo, Ribeirão Preto, SP, Brazil; fsguimar@fmrp.usp.br (F.S.G).

4 Center for Interdisciplinary Research on Applied Neurosciences (NAPNA), University of São Paulo, Brazil; fsguimar@fmrp.usp.br (F.S.G.).

5 Department of Biomedicine, Aarhus University, Aarhus, Denmark; sjoca@biomed.au.dk (S.R.L.J.).

* Correspondence: sjoca@biomed.au.dk; Tel.: (optional; include country code; if there are multiple corresponding authors, add author initials)

\begin{abstract}
Cannabidiol (CBD) is a non-intoxicating compound extracted from Cannabis sativa, showing antidepressant-like effects in different rodent models. However, inconsistent results have been described depending on the species and the strain used to assess depressive-like behaviour. Moreover, only a few studies have investigated the effect of CBD in female rodents. Therefore, we aimed to i) investigate the effects of CBD in two different strains of mice (Swiss and C57BL/6) and in a rat model of depression based on selective breeding (Flinders Sensitive and Resistant Lines, FSL and FRL) subjected to tests predictive of antidepressant-like effects; and ii) investigate the influence of sex in the effects of CBD in both mice and rats. CBD induced an antidepressant-like effect in male Swiss but not in female Swiss or C57BL/6 mice in the tail suspension test (TST). In male FSL rats, CBD produced an antidepressant-like effect one-hour post-injection. However, in female FSL, CBD induced a bimodal effect, increasing the immobility time at one hour and decreasing it at two hours. Ketamine produced an antidepressant-like effect in male and female FSL rats at different doses. In conclusion, strain, sex, and administration time affect CBD's behavioural response to rodents exposed to tests predictive of antidepressant effects.
\end{abstract}

Keywords: Cannabidiol; S-Ketamine; Sex; Mice strain; Flinders Sensitive Line rats; Tail suspension test; Forced Swim Test.

\section{Introduction}

Major depressive disorder (MDD) is a chronic and disabling psychiatric disorder [1]. The World Health Organization (WHO) estimates that over 300 million people suffer from depression worldwide [2,3] and that MDD is the major contributor to the world's burden of disease $[4,5]$. This scenario is further aggravated by the high prevalence and comorbidity of anxiety disorders, affecting more than $3.6 \%$ of the world population [2]. Consequently, there is a significant socioeconomic impact with increasing health-related costs and a reduction in the productivity of the economically active population [6,7]. Importantly, there is a considerable sex imbalance in MDD and anxiety prevalence, with depression being twice more prevalent in women than men [2,3]. Despite that, the use of females to investigate new drugs and neuropathology is scarce in basic research [8-10]. Eighty \% of the preclinical research in behavioural neuroscience has been developed in 
male subjects [11], which can potentially limit the benefit of the discoveries for females and compromise the development of personalized medicine [8,11-13].

Cannabidiol (CBD) is one of the main active constituents present in Cannabis sativa [14]. Unlike delta-9-tetrahydrocannabinol ( $\Delta$ 9-THC), it does not induce psychostimulant effects, nor is associated with an increased risk of abuse and dependence [15]. Due to its non-intoxicating properties and multi-targeted action [16,17], the therapeutic properties of CBD have been investigated in several animal models of neurological and psychiatric disorders, with promising results [18]. The anxiolytic effect of CBD has been shown in different animal models [19-21] and clinical trials [19-21]. Although consistent data from humans are still lacking [16], the antidepressant properties of CBD have been consistently demonstrated in different behavioural readouts, such as the Forced Swim Test (FST) [2226], Tail Suspension Test (TST) [27], Learned Helplessness (LH) [24], Olfactory Bulbectomy (OBX) [28], and Chronic Unpredictable Mild Stress (CUMS) [29,30]. Moreover, $\mathrm{CBD}$ is also able to rescue the behavioural phenotype of congenitally depressed rat strains, such as the Wistar-Kyoto (WKY) [31,32] and Flinders Sensitive Line (FSL) rats [24,32]. Interestingly, CBD produces a rapid and sustained antidepressant-like effect in rodents, similar to ketamine [24]. This characteristic places CBD as an interesting new drug to successfully treat depression and anxiety.

However, most studies investigating CBD antidepressant effects have been performed in male rodents [16]. More recently, Shbiro and colleagues [32] investigated the effects of CBD in both females and males WKY and FSL rats and reported that CBD induced antidepressant-like effects in male and female WKY and male FSL rats [32]. However, in this study, the authors investigated only one dose of CBD (30 mg/kg), making it difficult to conclude that CBD lacks effects in female FSL rats since this drug is known to produce an inverted U-shape dose-response curve [24,26,33,34]. Moreover, significant variability in CBD effective doses have been observed (10-200 mg/kg), depending on the rodent species and strain, treatment time, and test used (reviewed by [16]. Indeed, a growing body of evidence suggests that strain and species of the selected rodents may affect baseline behavioural measurements in distinct paradigms [35-41]. These factors may also influence the drug response, interfering with the effective dose range $[36,37,40,42]$ or causing the absence of effect in different tests $[37,38,43]$.

Therefore, we herein examined CBD anxiolytic and antidepressant-like effects in both sexes of different rodent species (rats and mice). More specifically, the present study aimed to investigate whether CBD treatment could produce i) an anxiolytic and antidepressant-like effect in male and female Swiss and C57BL/6 mice submitted to TST and elevated plus maze (EPM), two most used mice strain; ii) an antidepressant-like effect in male and female FSL rats exposed to FST at different time-points ( 1 and 2 hours before the test).

\section{Results}

\subsection{Swiss and $\mathrm{C} 57 \mathrm{BL} / 6$ mice}

2.1.1. CBD effects in male and female Swiss and C57BL/6 mice submitted to the elevated plus-maze (EPM) and TST

A three-way ANOVA was performed to examine the effect of treatment, sex, and strain mice (Swiss and C57BL/6) on the parameters evaluated in the TST and EPM. There was a significant effect of the treatment (Three-way ANOVA: F(4, 141)=7.69; $\mathrm{p}<0.001$ ) and mice strain on immobility in the TST (Three-way ANOVA: F $(4,141)=289.7 ; p<0.001$ ). Swiss mice present greater immobility compared to C57BL/6 mice. Moreover, there was an interaction between treatment vs $\operatorname{sex}(\mathrm{F}(4,141)=3.31 ; \mathrm{p}=0.013)$, and a statistical tendency in the interaction treatment vs strain $(\mathrm{F}(4,141)=2.21 ; \mathrm{p}=0.07)$.

Since there was a significant effect on the strain and a tendency in the interaction (treatment vs strain), we performed an independent two-way ANOVA to evaluate the treatment and sex effects in each mice strain, Swiss and C57BL/6. In Swiss mice, the twoway ANOVA revealed a significant effect of the treatment $(F(4,56)=5.21 ; p=0.001)$ and the 
interaction (sex vs treatment; $\mathrm{F}(4,56)=2.54 ; \mathrm{p}=0.05$ ). Afterwards, a one-way ANOVA was performed on each sex to compare the treatment effect on immobility. In male Swiss mice, a single injection of imipramine (IMIP) and all doses of CBD decreased immobility time in the TST (One-way ANOVA: $\mathrm{F}(4,25)=8,657$; $\mathrm{p}=0.0002$; Dunnett test: IMIP, $\mathrm{p}<0.0001$; CBD $3 \mathrm{mg} / \mathrm{kg}$, p=0.0159; CBD $10 \mathrm{mg} / \mathrm{kg}, \mathrm{p}=0.0038$; CBD $30 \mathrm{mg} / \mathrm{kg}$, p=0.0182; Cohen test: VEH x IMIP: $d=3.983$; VEH x CBD groups: $\mathrm{f}=0.70$; Figure 1B), suggesting an antidepressant-like effect. However, none of the drug treatments modified the analyzed parameters in female Swiss mice (Kruskal-Wallis test: $\mathrm{H}(5)=6.153 ; \mathrm{p}=0.188$; Figure 2B). A two-way ANOVA showed no effect on C57BL/6 mice (Figures 3B and 4B).

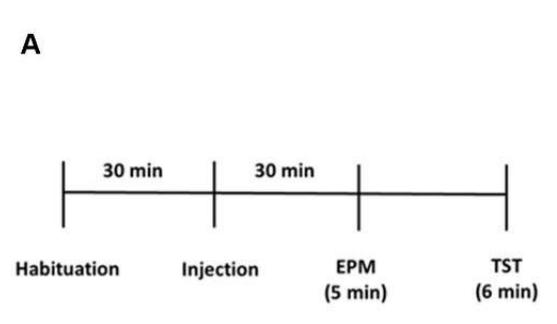

B

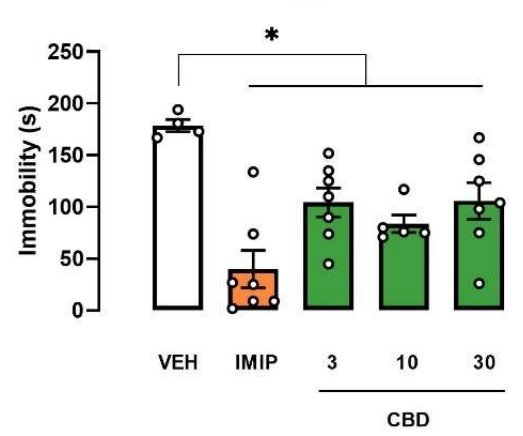

D

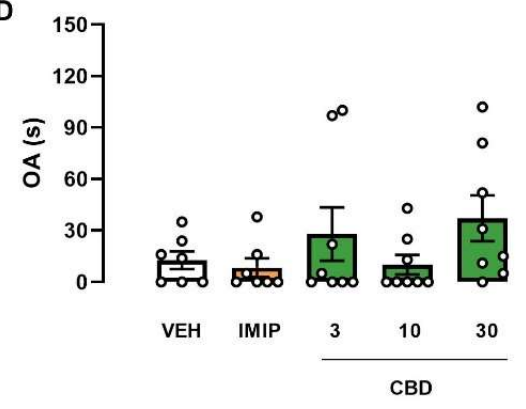

E

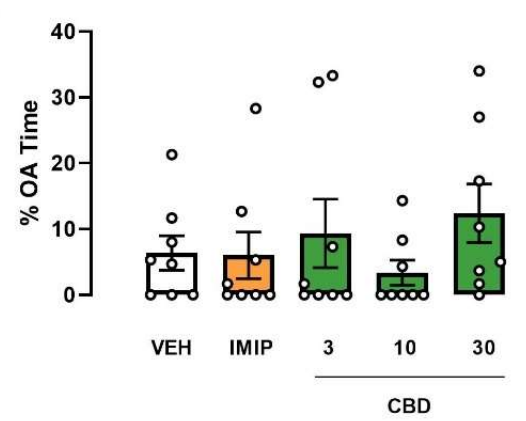

C
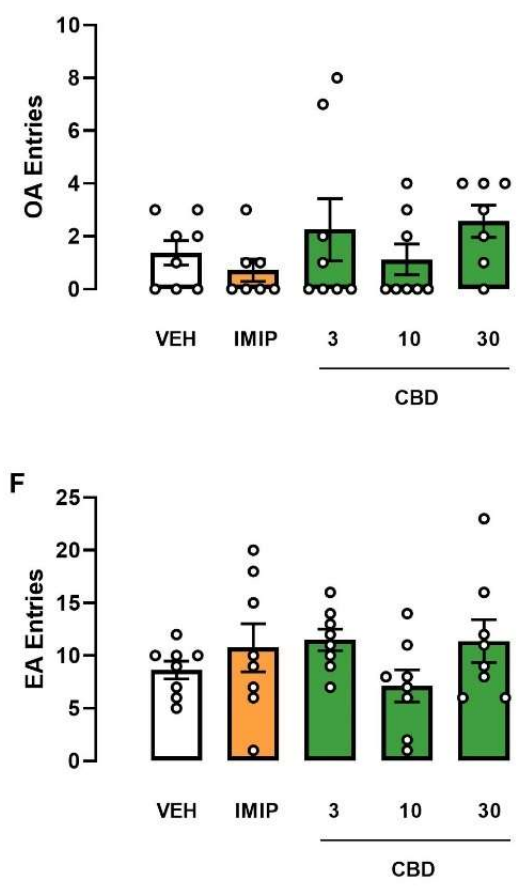

Figure 1. Effects induced by cannabidiol (CBD) in male Swiss mice submitted to tail suspension test and elevated plus-maze. Experimental scheme (A). Effect of cannabidiol (CBD) in male Swiss mice administered 30 min before the exposure to TST (B), EPM (C, D, E, F). Bars represent the immobility time (s) in the TST, OA spent time and percentage spent time, OA and EA entries in the EPM. Values are mean \pm SEM; Asterisks represents significant treatment difference from control $\left({ }^{*} \mathrm{p}<0.05\right.$; One-way ANOVA followed by Dunnett post hoc test), $\mathrm{n}=4-8$ animals/group. CBD: cannabidiol; EA: enclosed arm; IMIP: imipramine; OA: open arm; VEH: vehicle. 

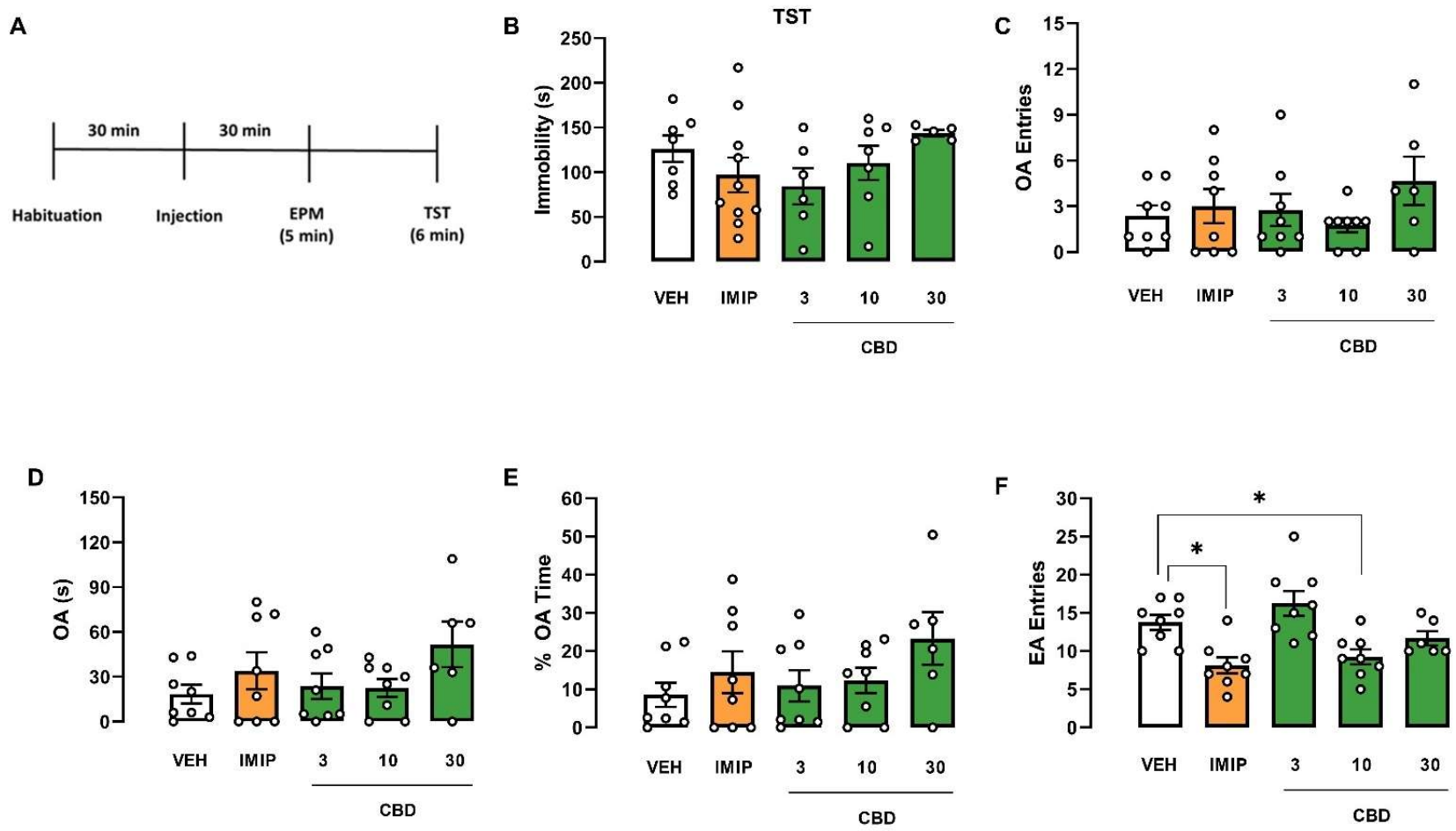

Figure 2. Effects induced by cannabidiol (CBD) in female Swiss mice submitted to the tail suspension test and elevated plusmaze. Experimental scheme (A). Effect of cannabidiol (CBD) in female Swiss mice administered 30 min before the exposure to the TST (B) and EPM (C, D, E, F). Bars represent the immobility time (s) in the OA spent time and percentage spent time, OA, and EA entries in the EPM. Values are mean \pm SEM; Asterisks represents significant treatment difference from control $\left({ }^{*} \mathrm{p}<0.05\right.$; One-way ANOVA followed by Dunnett post hoc test), n= 5-10 animals/group. CBD: cannabidiol; EA: enclosed arm; IMIP: imipramine; OA: open arm; VEH: vehicle. 

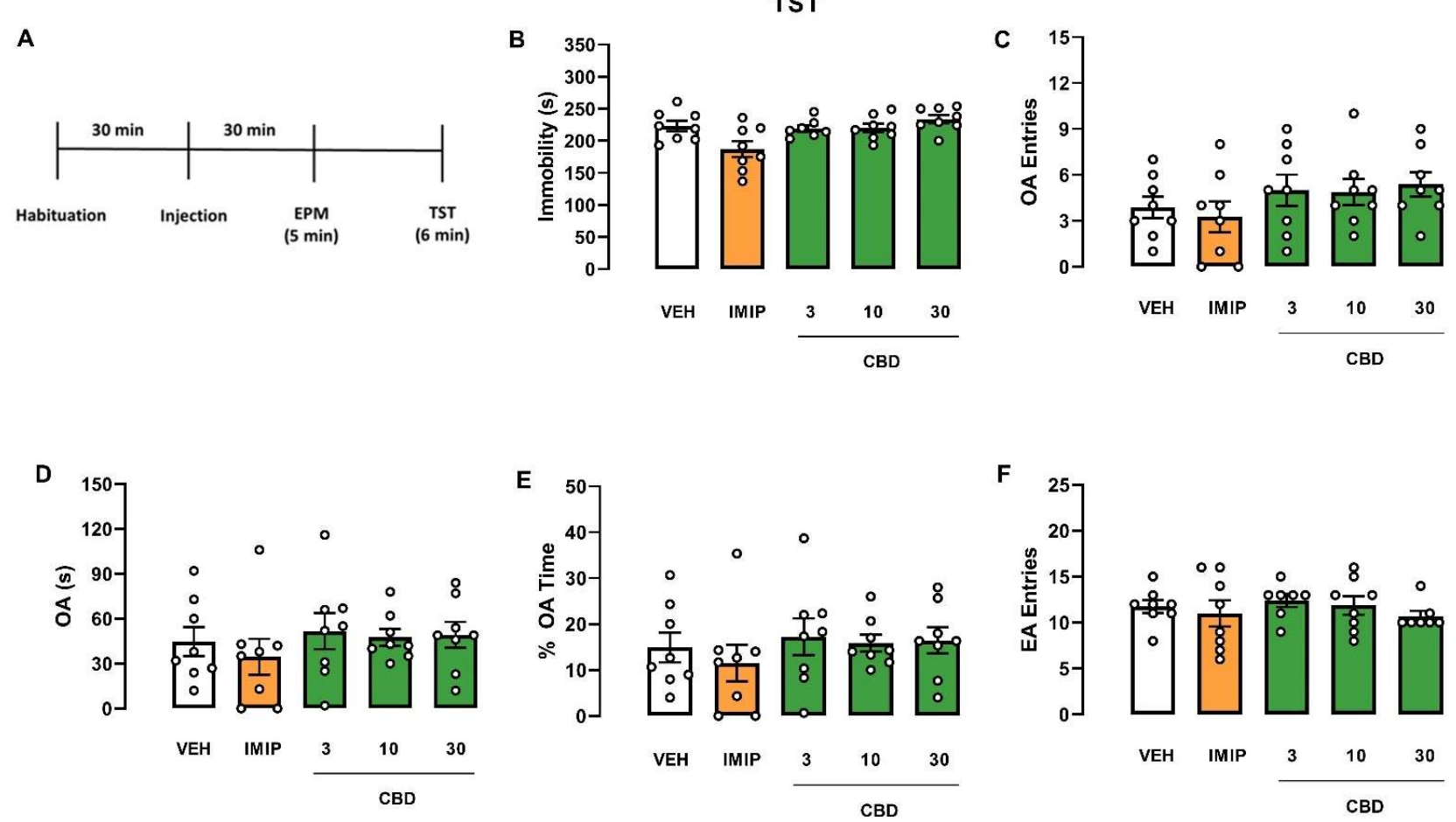

Figure 3. Effects induced by cannabidiol (CBD) in male C57BL/6 mice submitted to the tail suspension test and elevated plusmaze. Experimental scheme (A). Effect of cannabidiol (CBD) in male C57BL/6 mice administered 30 min before the exposure to the TST (B) and EPM (C, D, E, F). Bars represent the immobility time (s) in the TST, OA spent time and percentage spent time, OA and EA entries in the EPM. Values are mean \pm SEM; $n=7-8$ animals/group. CBD: cannabidiol; EA: enclosed arm; IMIP: imipramine; OA: open arm; VEH: vehicle. 


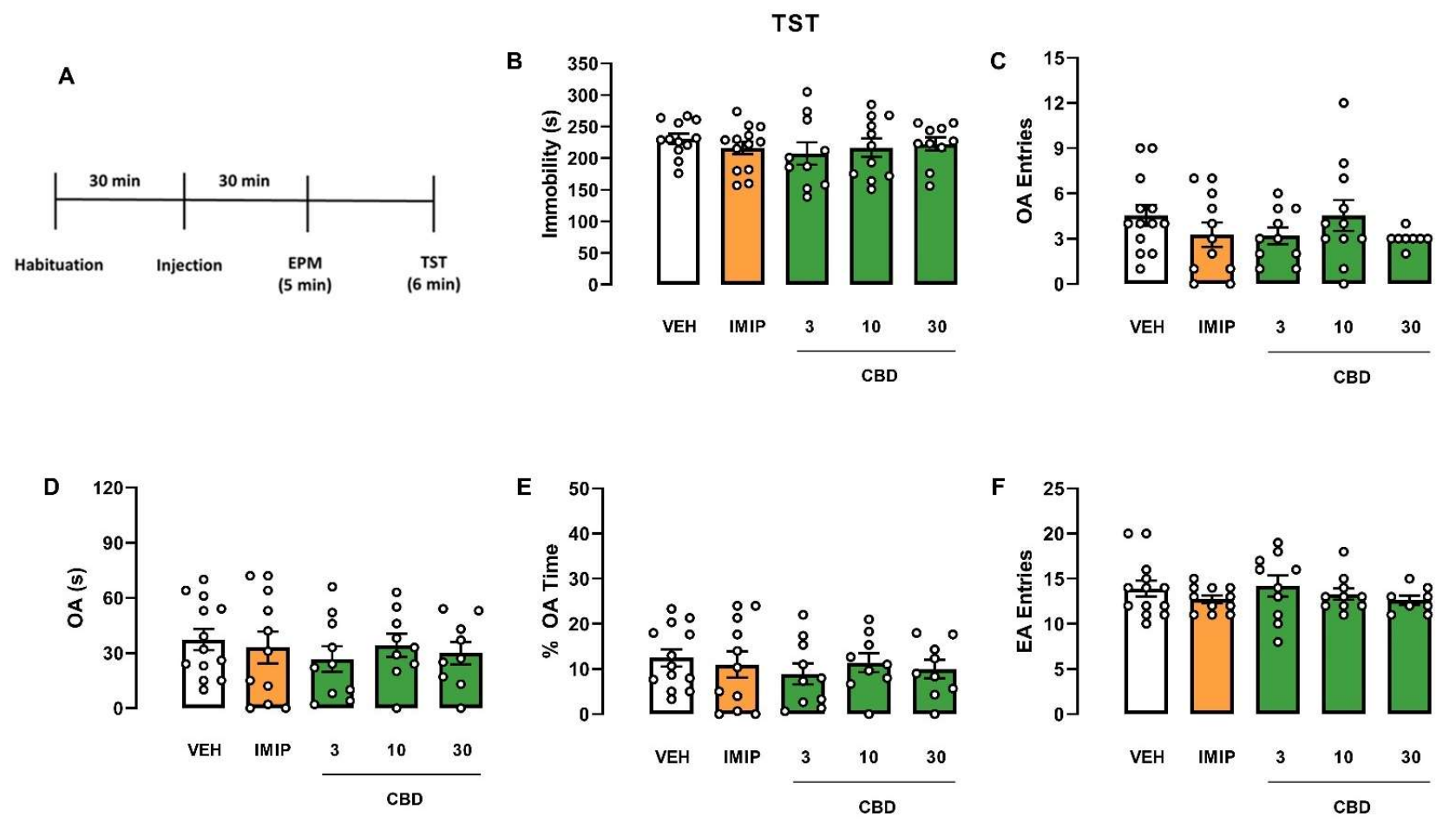

Figure 4. Effects induced by cannabidiol (CBD) in female C57BL/6 mice submitted to the tail suspension test and elevated plusmaze. Experimental scheme (A). Effect of cannabidiol (CBD) in female C57BL/6 mice administered 30 min before the exposure to TST (A) and EPM (B, C, D, E). Bars represent the immobility time (s) in the TST, OA spent time and percentage spent time, OA and EA entries in the EPM. Values are mean \pm SEM; $n=9-13$ animals/group. CBD: cannabidiol; EA: enclosed arm; IMIP: imipramine; OA: open arm; VEH: vehicle.

Regarding the anxiety-related behaviour assessed in the EPM, a three-way ANOVA revealed a significant strain effect (Three-way ANOVA: $F(1,150)=22.43$; $p<0.001$ ), interaction sex vs strain (Three-way ANOVA: $\mathrm{F}(1,141)=7.84 ; \mathrm{p}<0.001)$, and no treatment effect on the OA entries, revealing that C57BL/6 mice explore OA more than Swiss mice. The difference is greater in male than female animals. Moreover, there was a significant sex vs strain interaction in the percentage of time spent in the OA (Three-way ANOVA: F(1, $151)=10.74 ; \mathrm{p}=0.001)$, revealing that male Swiss mice spent less time exploring the OA than their female counterpart. In $\mathrm{C} 57 \mathrm{BL} / 6$ mice, the exploratory response was similar between gender (Figure 1E, 2E, 3E, and 4E).

Furthermore, in the time spent in the OA, a three-way ANOVA revealed a significant difference in the sex (Three-way ANOVA: $F(1,148)=12.84 ; \mathrm{p}<0.001$ ), strain (Three-way ANOVA: $F(1,148)=9.58 ; \mathrm{p}<0.001$ ), and the treatment vs strain interaction (Three-way ANOVA: $F(1,148)=2.80 ; \mathrm{p}=0.028)$, demonstrating that female mice spent more time exploring the OA compared to males. Following the significant treatment vs strain interaction, we performed a two-way ANOVA to evaluate the treatment and strain effects in Swiss and C57BL/6 mice. There was no difference in C57BL/6 mice (Figure 3 and 4). On the other hand, there was a significant treatment effect on the OA of the Swiss mice (Twoway ANOVA: $F(4,73)=4.08 ; \mathrm{p}=0.005)$. However, a one-way ANOVA or Kruskal-Wallis in each sex of the Swiss mice failed to find a significant effect in this parameter (Male: Kruskal-Wallis test: $\mathrm{H}(5)=4.792 ; \mathrm{p}=0.3094$; Figure 1D; Female: One-way ANOVA: F(4, 148)= 1.646; $\mathrm{p}=0.1862$; Figure 2D).

Concerning the EA entries, a three-way ANOVA revealed a significant treatment effect in this behavioural response $(\mathrm{F}(4,148)=5.85 ; \mathrm{p}=0.001)$. Only in female Swiss mice imipramine and CBD $10 \mathrm{mg} / \mathrm{kg}$ treatment reduced the EA entries in the EPM compared to 
VEH-treated mice (One-way ANOVA: $\mathrm{F}(4,33)=8.305$; $\mathrm{p}<0.001$; Dunnett test: IMIP, $\mathrm{p}=0.0054$; CBD $10 \mathrm{mg} / \mathrm{kg}, \mathrm{p}=0.0310$; Figure $2 \mathrm{~F}$ ). There was no significant correlation between immobility time and EA entries in the IMIP and CBD $10 \mathrm{mg} / \mathrm{kg}$ treated group (Correlation: IMIP, r= -0.5697; $\mathrm{p}=0.1405$; CBD10, $\mathrm{r}=0.1224$; $\mathrm{p}=0.7937$; data not shown). Therefore, the alteration in the locomotor activity did not affect the immobility in the TST. There was no statistical difference in male Swiss (Figure 1F) and C57BJ/6 mice of both sexes (Male: Figure 3F; Female: Figure 4F).

In summary, CBD only induced an antidepressant-like effect in male Swiss mice without affecting the locomotor activity, but not in females from the same strain. Moreover, CBD did not affect the TST and EPM behaviours in male and female C57BL/6 mice.

\subsection{FSL rats}

2.2.1. Dose-response curve of ketamine in female FSL rats exposed to the OFT/FST.

As expected, ketamine $15 \mathrm{mg} / \mathrm{kg}$ and $20 \mathrm{mg} / \mathrm{kg}$ reduced the immobility in FSL rats exposed to the FST (Kruskal-Wallis test: $\mathrm{H}(4)=10.60 ; \mathrm{p}=0.0141$; Dunn's and Cohen d test: Ketamine $15 \mathrm{mg} / \mathrm{kg}, \mathrm{p}=0.0198, \mathrm{~d}=1.838$; Ketamine $20 \mathrm{mg} / \mathrm{kg}, \mathrm{p}=0.0108, \mathrm{~d}=3.350$; Figure 5B). FSL rats treated with vehicle had significantly higher immobility time when compared with FRL rats treated with vehicle (Mann-Whitney test: $U=6.5 ; p=0.0037$; Figure 5B), which characterized a depressive-like phenotype. Neither rat strain (Student's t-test: $\mathrm{t}(15)=0.7981 ; \mathrm{p}=0.4373$ ) nor drug treatment (One-way ANOVA: $\mathrm{F}(3,24)=0.6495 ; \mathrm{p}=0.5910$; Figure 5C) changed the OFT locomotor activity in FSL rats.

A

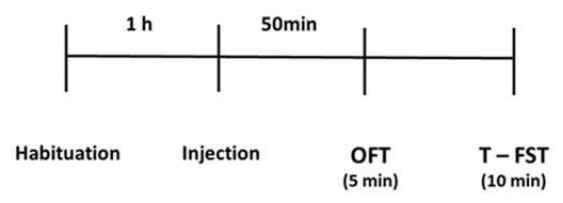

B

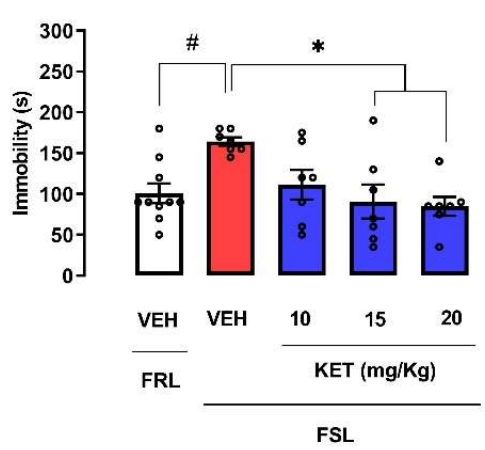

C

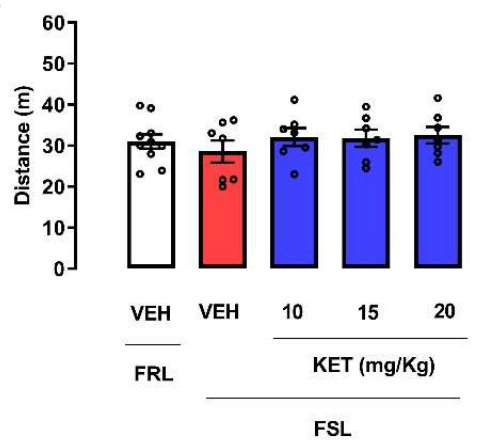

Figure 5. Dose-response curve of S-ketamine in female FSL rats submitted to the forced swim and open field tests. Experimental scheme (A). The rats were treated with VEH or ketamine $(10,15$, and $20 \mathrm{mg} / \mathrm{kg}) 1$ hour before the exposition to the FST (B) and OFT (C). Bars represent the immobility time (s) in the FST or the travelled distance (m) in the OFT. Values are mean \pm SEM; Hash indicate significant differences between FSL and FRL vehicle-treated groups (\#p<0.05, Student's t-test or Mann-Whitney test); Asterisks represents significant treatment difference from FSL control $\left({ }^{*} \mathrm{p}<0.05\right.$; Kruskal-Wallis followed by Dunn's post hoc), $\mathrm{n}=7-10$ animals/group. FST, Forced swimming test; OFT, open field test; KET, S-Ketamine; VEH, vehicle.

2.2.2. Effect produced by CBD administered 1 or 2 hours before the OFT/FST in male and female FSL rats.

A three-way ANOVA was performed to examine the effect of treatment, sex, and time in the parameters evaluated in the FST and OFT. There was a significant effect of treatment (Three-way ANOVA: $\mathrm{F}(4,94)=10.29$; $\mathrm{p}<0.001$ ), sex (Three-way ANOVA: $\mathrm{F}(1,94)=25.48 ; \mathrm{p}<0.001$ ), between treatment vs time (Three-way ANOVA: $\mathrm{F}(2,94)=3.82$; $\mathrm{p}=0.025)$, sex vs time (Three-way ANOVA: $\mathrm{F}(1$, $94)=28.53 ; \mathrm{p}<0.001$ ) and treatment vs sex vs time (Three-way ANOVA: $\mathrm{F}(2,94)=15.41 ; \mathrm{p}<0.001)$ interactions in the immobility in the FST.

Furthermore, in the total distance travelled in the OFT, there was a significant effect of treatment (Three-way ANOVA: $\mathrm{F}(4,94)=12.80 ; \mathrm{p}<0.001$ ), sex (Three-way ANOVA: $\mathrm{F}(1,94)=38.16$; $\mathrm{p}<0.001$ ), time (Three-way ANOVA: $\mathrm{F}(1,94)=7.32 ; \mathrm{p}<0.001$ ), treatment vs sex (Three-way ANOVA: $\mathrm{F}(4,94)=13.58 ; \mathrm{p}<0.001)$, treatment vs time (Three-way ANOVA: $\mathrm{F}(2,94)=3.96 ; \mathrm{p}=0.022$ ), sex vs time 
(Three-way ANOVA: $\mathrm{F}(4,94)=4.27 ; \mathrm{p}=0.04)$, and treatment vs sex vs time (Three-way ANOVA: $\mathrm{F}(2$, $94)=7.46 ; \mathrm{p}=0.0001$ ) interactions.

Since there was a significant effect in the interaction (treatment vs sex vs time) in the parameters assessed in FST and OFT, we performed an independent Student's t-test to compare the results between the rat strain, FRL and FSL vehicle-treated groups, and a one-way ANOVA followed by Dunnett post hoc test to evaluate the treatment effect in each sex and time in FSL rats. When the variances between the groups were not homogenous, the Mann-Whitney (for comparisons between FSL and FRL vehicle-treated groups) or Kruskal-Wallis followed by Dunn's post hoc tests were used to compare FSL rats treated with VEH, Ketamine, or CBD.

One hour after injection, male FSL rats treated with vehicle displayed significantly increased immobility time compared with FRL rats treated with vehicle (Student's t-test: $t(17)=5.126$; $\mathrm{p}<$ 0.0001; Figure 6C). FSL rats treated with CBD (30 mg/kg) or KET (15 mg/kg) showed a tendency to reduce immobility time (One-way ANOVA: $\mathrm{F}(4,29)=3.178 ; \mathrm{p}=0.0279$; Dunnett test: CBD $30 \mathrm{mg} / \mathrm{kg}$, $\mathrm{p}=0.0826$; KET, $\mathrm{p}=0.0523$; Cohen $\mathrm{d}$ test: FSL-VEH $\times$ FSL-KET, $\mathrm{d}=1.218$; FSL-VEH $\times$ FSL-CBD 30 $\mathrm{mg} / \mathrm{kg}, \mathrm{d}=1.153$; Figure $6 \mathrm{C})$, suggesting an antidepressant-like effect. Neither rat strain $(\mathrm{t}(17)=$ 0.5769; $\mathrm{p}=0.5716$ ) nor drug treatment (One-way ANOVA: $F(4,29)=0.3576 ; \mathrm{p}=0.8366$; Figure 6E) changed the locomotor activity in FSL rats.

Two hours after injection, male FRL treated with vehicle presented lower immobility (Student's t-test: $\mathrm{t}(16)=5.241 ; \mathrm{p}<0.0001$; Figure 6D) and increased locomotion (Student's t-test : $\mathrm{t}(16)=$ 2.722; $\mathrm{p}=0.0151$; Figure 6F) in comparison with vehicle-treated FSL animals. As demonstrated previously, Ketamine $(15 \mathrm{mg} / \mathrm{kg}$ ) injected 1 hour before FST reduced immobility in FSL rats (KruskalWallis test: $\mathrm{H}(3)=14.52 ; \mathrm{p}=0.0007$; Dunn's: $\mathrm{p}=0.0007$; Cohen $\mathrm{d}$ test: $\mathrm{d}=1.749$; Figure 6D). CBD did not change immobility in the test 2 hours later (Kruskal-Wallis test: $\mathrm{H}(3)=14.52 ; \mathrm{p}=0.0007$; Dunn's: p> 0.9999; Figure 6D). None of treatment changed the distance traveled in the OFT (One-way ANOVA: $\mathrm{F}(2,27)=0.3255 ; \mathrm{p}=0.7250$; Figure $6 \mathrm{~F})$. 
A

1 hour

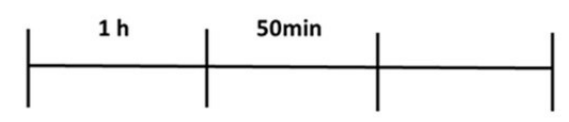

Habituation Injection $\quad \begin{array}{cc}\text { OFT } & \text { T - FST } \\ (5 \mathrm{~min}) & (10 \mathrm{~min})\end{array}$

$1 \mathrm{~h}$
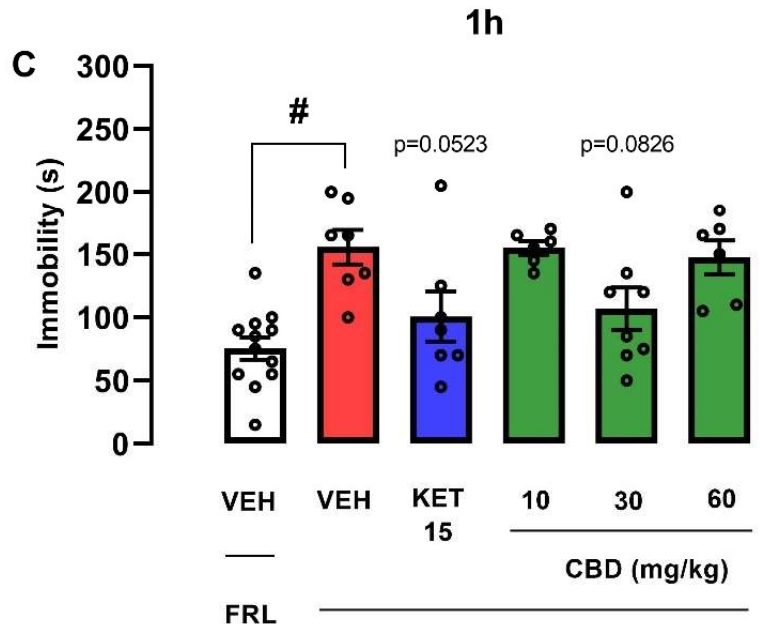

FSL

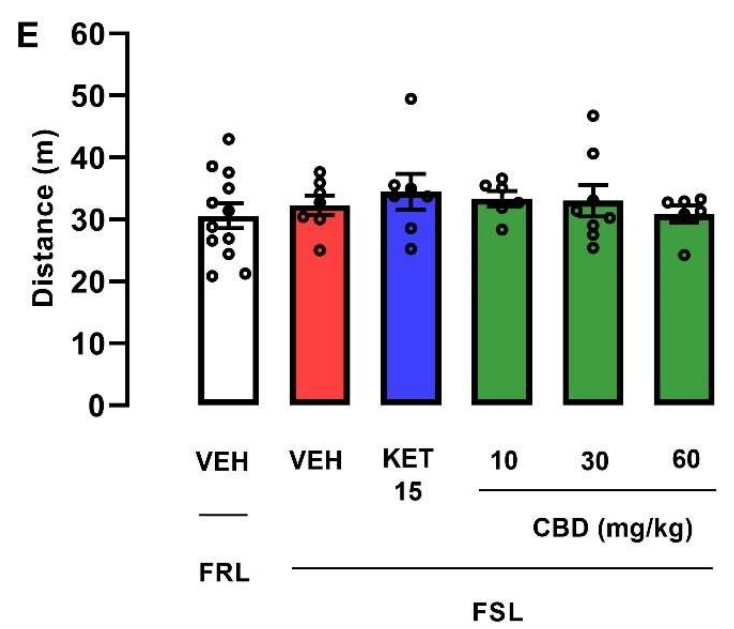

B

\section{2 hours}

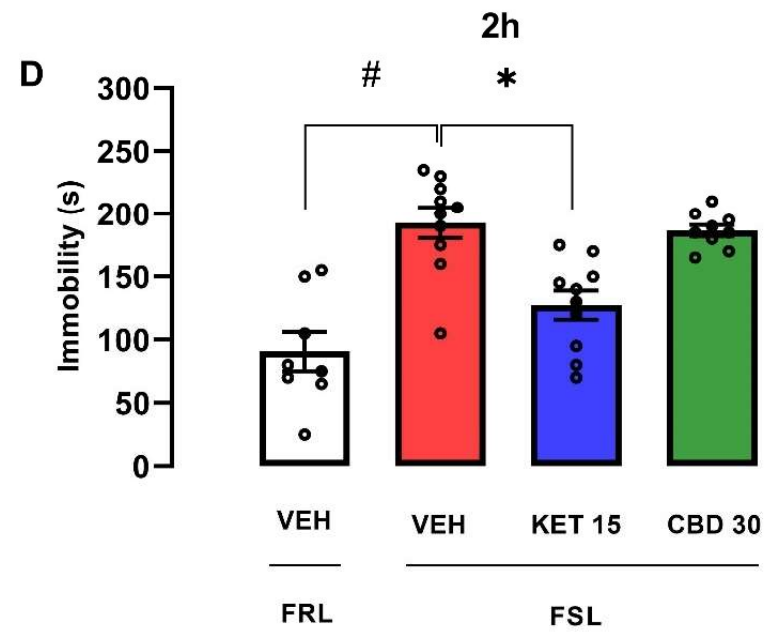

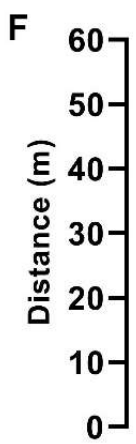

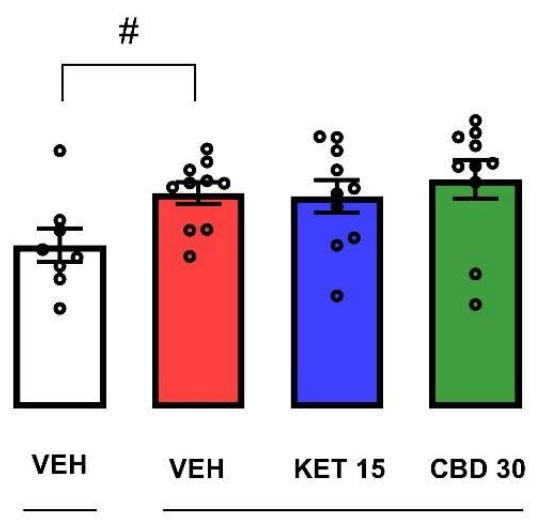

FRL

Figure 6. Effects of cannabidiol (CBD) administered 1 or 2 hours before the forced swim and open field tests in male FSL rats. Experimental scheme (A, B). Effect of cannabidiol (CBD) in male FSL rats administered 1 (C, E) or 2 hours (D, F) before the FST and OFT. Bars represent the immobility time (s) in FST or the travelled distance $(\mathrm{m})$ in the OFT. Values are mean \pm SEM; Hash indicates significant differences between FSL and FRL vehicle-treated groups ( $\# \mathrm{p}<0.05$, Student's t-test); Asterisks represents significant treatment difference from FSL control ( ${ }^{*} p<0.05$; One-way ANOVA followed by Dunnett post hoc test or Kruskal-Wallis followed by Dunn's post hoc), $\mathrm{n}=6-12$ animals/group. CBD, Cannabidiol; FST, Forced swimming test; OFT, open field test; KET, S-Ketamine; VEH, vehicle. 
On the other hand, female FSL rats treated with vehicle displayed significantly increased immobility time when compared with FRL rats treated with vehicle (Student's t-test: $t(12)=2.954 ; \mathrm{p}=$ 0.0120; Figure 7C). They also showed a significant decrease in locomotion (Mann-Whitney: U=8; $\mathrm{p}=0.0426$; Figure 7E). However, female FSL rats treated with the intermediate dose of CBD $(30 \mathrm{mg} / \mathrm{kg}$ ) showed a tendency to increase immobility in the FST $1 \mathrm{~h}$ after treatment (One-way ANOVA: $F(4,24)=9.464 ; p<0.0001$; Dunnett test: $p=0.0898$; Figure $7 C)$, suggesting a depressive-like effect. In contrast, the FSL rats treated with ketamine $(20 \mathrm{mg} / \mathrm{kg})$ showed a significant reduction the immobility (One-way ANOVA: $\mathrm{F}(4,24)=9.464 ; \mathrm{p}<0.0001$; Dunnett test: $\mathrm{p}=0.0096$; Figure $7 \mathrm{C}$ ). No drug treatment in FSL rats affected the locomotor activity (Kruskal-Wallis test: $\mathrm{H}(5)=5.917$; $\mathrm{p}=$ 0.2054; Figure 7E).

Two hours after injection, female FSL rats treated with vehicle displayed significantly increased immobility time when compared with FRL rats treated with vehicle (Student's $\mathrm{t}$-test: $(\mathrm{t}(8)=$ 3.076; $\mathrm{p}=0.0152$; Figure 7D). They also presented a tendency to decrease the distance traveled in OFT $(t(8)=1.861 ; p=0.0998$; Figure 7D). Interestingly, 2 hours after treatment CBD $(30 \mathrm{mg} / \mathrm{kg})$, in female FSL rats, reduced the immobility (One-way ANOVA: $F(2,15)=4.439 ; p=0.0306$; Dunnett test: $p=0.018$; Cohen d test: $d=1.621$; Figure 7D). Ketamine $(20 \mathrm{mg} / \mathrm{kg})$ injected 2 hours before the FST did not change the behaviour in the test (One-way ANOVA: $F(2,15)=4.439$; $p=0.0306$; Dunnett test: $\mathrm{p}=0.4096$; Figure 7D). No treatment modified the distance traveled in the OFT in FSL rats (One-way ANOVA: $F(2,15)=0.9503 ; \mathrm{p}=0.4087$; Figure $7 \mathrm{~F})$. 
A

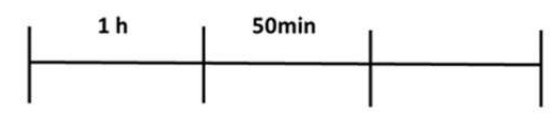

Habituation Injection $\quad \begin{array}{cc}\text { OFT } & \text { T - FST } \\ (5 \mathrm{~min}) & (10 \mathrm{~min})\end{array}$

$1 \mathrm{~h}$
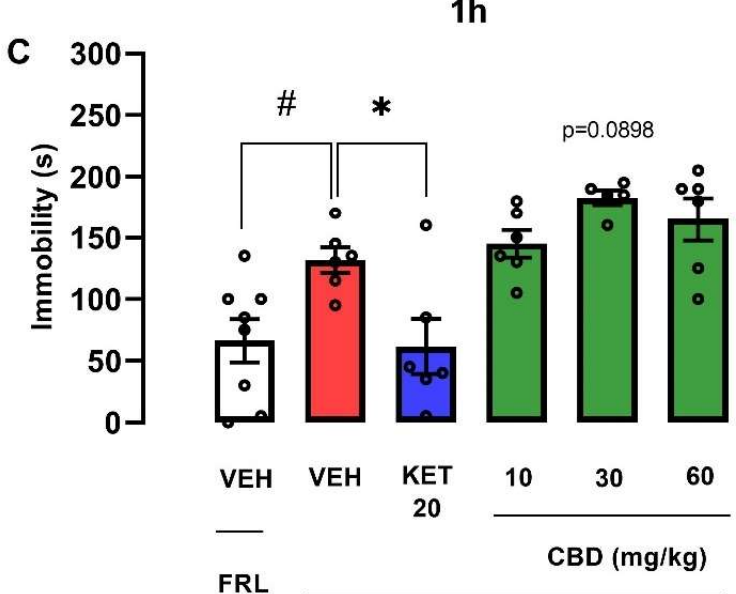

FSL

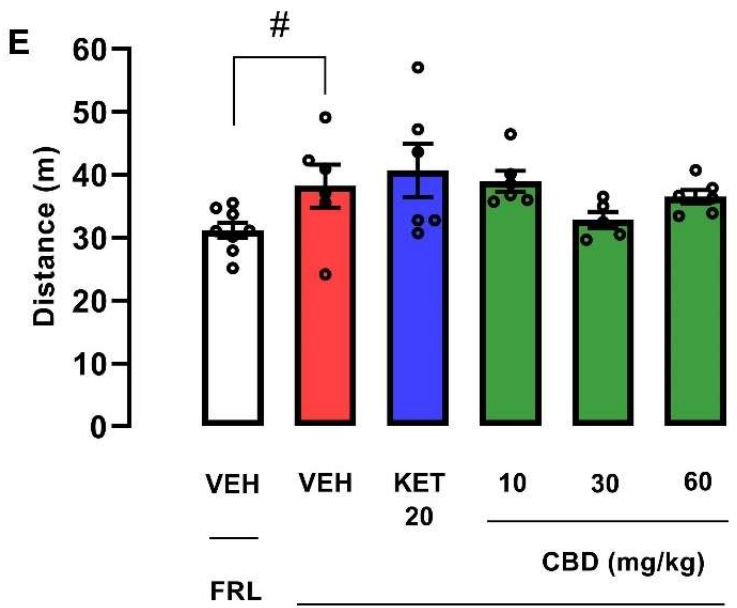

FSL
B

2 hours

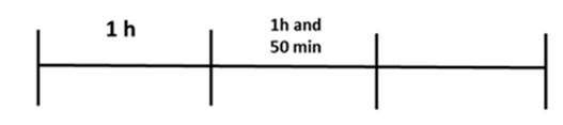

Habituation Injection $\begin{gathered}\text { OFT } \\ (5 \mathrm{~min})\end{gathered} \quad \begin{gathered}\text { T }- \text { FST } \\ (10 \mathrm{~min})\end{gathered}$

$2 \mathrm{~h}$
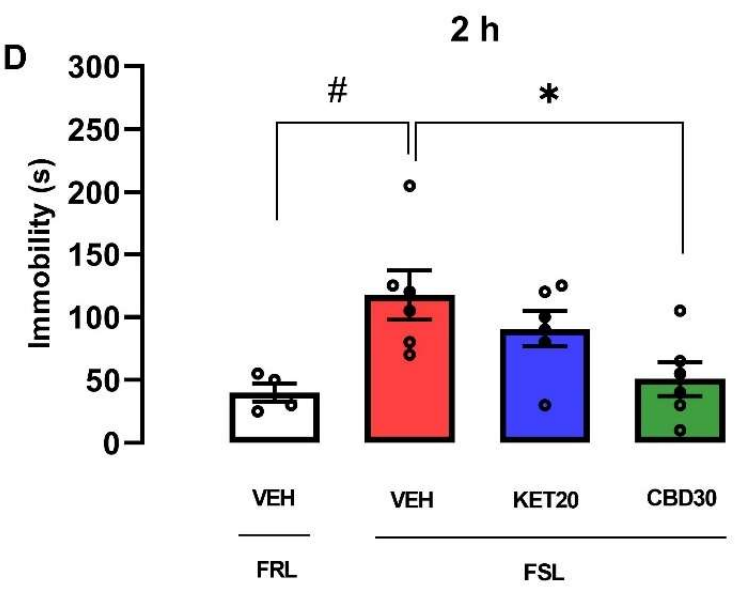

$\mathbf{F}$

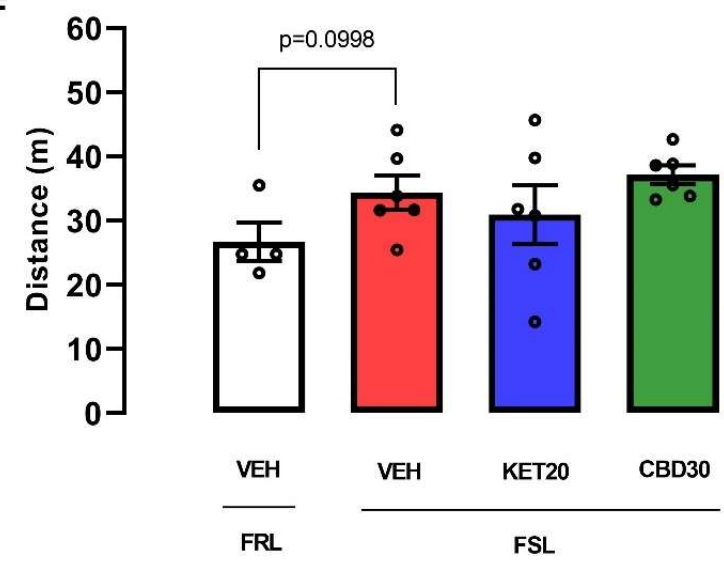

Figure 7. Effects of cannabidiol (CBD) administered 1 or 2 hours before the forced swim and open field tests in female FSL rats. Experimental scheme (A, B). Effect of cannabidiol (CBD) in female FSL rats administered 1 (C, E) and 2 hours (D, F) before the exposure to the FST and OFT. Bars represent the immobility time (s) in the FST or the travelled distance (m) in the OFT. Values are mean \pm SEM; hash indicates significant differences between FSL and FRL vehicle-treated groups (\#p $<0.05$, Student's t-test or MannWhitney test); asterisks represent significant treatment difference from FSL control rats $\left({ }^{*} \mathrm{p}<0.05\right.$; one-way ANOVA followed by Dunnett's post hoc), $\mathrm{n}=4-10$ animals/group. CBD, Cannabidiol; FST, Forced swimming test; OFT, open field test; KET, S-Ketamine; $\mathrm{VEH}$, vehicle. 


\section{Discussion}

The main finding of the present work is that CBD differentially modulates depressive-like behaviour depending on injection time, strain, species, and sex. This study is the first to systematically investigate CBD's behavioural and temporal effects in both sexes of FSL rats and different mice strains (Swiss and C57BL/6). Our main findings suggested that CBD produced an antidepressant-like effect only in male Swiss mice. Strikingly, CBD induced a bimodal effect in female FSL rats dependent on the injection time. In contrast, CBD tended to decrease the immobility time at 1 hour after the injection in males and did not produce any behavioural change at 2 hours.

Previous studies have reported that acute injection of CBD produces an antidepressant-like effect in male Swiss mice subjected to different predictive tests, including FST $[24-26,44]$ and TST [27]. On the other hand, in male C57BL/6 mice, CBD injection did not modify the behavioural response in the test. However, previous studies reported that acute and repeated $\mathrm{CBD}$ administration produced a behavioural response in male C57BL/6 mice submitted to OBX (LINGE et al., 2016) and CUMS $[45,46]$. Therefore, CBD antidepressant-like properties in C57BL/6 mice might depend on the experimental paradigm and treatment regimen (acute vs repeated administration).

On the other hand, in female mice, CBD did not change the immobility time in both Swiss and C57BL/6 mice submitted to the TST. This drug also produced an antidepressant-like effect in both female and male WKY rats submitted to the saccharine preference test and FST, but had no effect in female FSL rats [32].

The biological variable sex is a critical factor that affects the antidepressant drug response in different models [37,47-51] and can change the effective drug doses $[36,37,40]$. So, previous studies evidenced that females may be more sensitive to the effects of selective serotonin reuptake inhibitors (SSRIs). For example, acute administration with lower doses of fluoxetine [47,49], paroxetine [37], and sertraline [52] produce an antidepressantlike effect in female rats and mice exposed to the TST and FST compared to males. Moreover, similar sex differences were reported in animals with the fast-acting antidepressant drug ketamine [48,53].

In addition, previous work showed that a CBD i.p. injection takes 2 hours to reach its peak of maximum plasma concentration (Cmax) and produce its behavioural response in mice submitted to the marble-burying test [54]. However, several variables can influence the time to reach the Cmax, such as the route of administration, the vehicle used, animal species, and sex [54]. The assessment of the CBD effect at later time points could allow us to detect its antidepressant properties in female mice from both strains. However, this hypothesis warrants further investigations.

Corroborating the present results, a body of evidence has shown that the mice strain (Swiss and C57BL/6) influences the baseline behavioural [38,40,59-61], the response to establish antidepressant drugs [38,40,61], neurochemical profile [37], sensitivity to stress, and some biochemistry parameters [39], which could produce a significant impact on the CBD effect. Therefore, the CBD effect on male mice's anxiety-related behaviours seems to depend on the selected strain, the treatment regime, previous stressful experience, and the behavioural test chosen.

In male FSL rats, CBD showed a tendency to induce an antidepressant-like effect 1 hour after the injection in the FST and did not produce any behavioural change 2-hours post-injection. In accordance with these results, a previous study from our group has shown that CBD induces an antidepressant-like effect one hour after administration but no sustained effect seven days later in FSL rats [24]. The observed CBD acute effect is consistent with previous studies, which reported that CBD acute injection significantly decreases the immobility in the FST [23,55], reduces the number of failures and increases the number of escapes in LH [24]. Indeed, increasing the group size could confirm the CBD effect in male FSL rats.

Moreover, our study also adds more time points and doses to the preliminary evidence showing that CBD could produce a hedonic and antidepressant-like effect in the 
FSL and WKY rats [32]. On the other hand, CBD had a hedonic and antidepressant-like effect in WKY and FSL rats 2 hours after oral administration [31,32]. The discrepancy in the behavioural results can be explained by the different tests used and the complex pharmacology of CBD. First, CBD has a lipophilic molecular structure, affecting solubility and making the choice of the correct dose tricky [14,56]. Second, the differences in the absorption profile between oral versus i.p. routes could have resulted in different plasma level kinetics. Indeed, oral administration may result in irregular absorption and suffer interference from a significant first-pass metabolism. Moreover, the animals' preexisting feeding conditions may have interfered with gastric emptying, ultimately leading to an erratic plasmatic concentration $[57,58]$. In the i.p. route, the absorption is faster, and the first pass metabolism occurs to a less extension [58,59]. Given the complex pharmacology of CBD, further studies testing different doses of CBD and using different routes of administration, time-points, and CBD plasma measurements should be performed.

Notably, in female FSL rats, CBD (30 mg/kg) produced an antidepressant-like effect only 2 hours after treatment. However, 1-hour following the administration, the same dose tended to induce a depressive-like effect. The existence of a sex difference may not be surprising. Consistent with our results, CBD did not change females' behavioural response in the FST and saccharin preference test but induced an antidepressant-like effect only in male FSL rats [32]. Measurements of CBD plasma levels in these two time points are also needed to clarify these results.

What could then be the neurobiological explanation behind the sex differences observed in our work? One explanation may be given in the physio-chemical properties of CBD. CBD has a chemical structure that confers high lipophilicity similar to delta-9-tetrahydrocannabinol $(\triangle 9-\mathrm{THC})[14,56]$. Therefore, it rapidly penetrates highly vascularized tissues in a short time, accumulates in fat tissue, and suffers redistribution, modifying the plasmatic concentration of the drug [60]. Consequently, this process can be affected by body weight and composition, which varies between sexes [60-63]. CBD presents a similar molecular structure to $\triangle 9$-THC [64-66], and studies show the profound influence of sex on $\triangle 9$-THC metabolism in the rat liver $[67,68]$. Adult female rats presenting high blood levels of the hydroxylated metabolite, 11-hydroxy- $\Delta 9-\mathrm{THC}$, than males [68]. Therefore, it is likely that these factors can influence the plasmatic and brain concentration of CBD and, consequently, differentially impact the behavioural effects observed among different sexes.

Anxiety disorders are frequently observed as a comorbidity in depressed patients $[69,70]$. However, in contrast to our expectations, CBD did not affect the anxiety-related behaviours in the EPM in male and female mice from both mice strains (Swiss and C57BL/6 mice). Previous works showed similar findings in male C57BL/6J mice, in which CBD acutely administered did not change the anxiety-related behaviours in different tests $[71,72]$. Moreover, consistent with our results in females, acute and repeated administration of CBD did not produce an anxiolytic effect in adolescent and adult female C57BL/6J mice [71]. However, CBD chronic administration did cause an anxiolytic effect after 21 days in male C57BL/6JArc mice in the OFT and light-dark test [72]. It also prevented, after 14 days), the anxiogenic effect induced by chronic stress in the novelty suppressed feeding and EPM tests [45,46]. Until now, CBD effects on anxiety-related behaviours have not been investigated in female Swiss mice.

The present study is also the first study to perform a dose-effect curve in female FSL rats. We showed that a single injection of ketamine (15 and $20 \mathrm{mg} / \mathrm{kg}$ ) produces an antidepressant-like effect in female FSL rats exposed to FST. Our finding strengthens previous results showing the efficacy of the treatment with ketamine in female rats, even though the effective doses vary in comparison to males [73-77]. In agreement with these results, our group has recently shown that ketamine responses in FSL rats are associated with a sex difference in the hippocampus morphology, alteration of hippocampal astrocytes, and brain-derived neurotrophic factor (BDNF) [78]. More studies are necessary to investigate how these differences are involved in the ketamine effect in female FSL rats. 
Notwithstanding, there are a few limitations in the present work. Most importantly, it would have been relevant to measure CBD plasma and brain levels. It would also be interesting to consider the oestrous cycle in females and how it may affect the basal response in the tests [79-82]. Even if it seems not to modulate the FST response in female FSL rats [83], it could have influenced the drug effects of the other tested species. Due to the limitations of the TST as a model of depression $[84,85]$, it would be interesting to investigate the effect of CBD using additional preclinical models. Finally, a positive control group in the EPM using an anxiolytic benzodiazepine could have helped to confirm the lack of CBD effect in anxiety-related behaviours in both sexes and strains of the used mice [86-88].

\section{Materials and Methods}

4.1. Animals

We use adult male and female Swiss and C57BL/6 mice (8 weeks old) from the University of São Paulo (SP) breeding facility, and adult male and female Flinders Sensitive Line (FSL) and Flinders Resistant Line rats (FRL; control of genetic background) (Weighing: male: 200.1 to 405.27 g; female: 138.15 to 216 g; 8 to 12 weeks old) from breeding colonies at Translational Neuropsychiatry Unit (Aarhus University; Denmark). The mice were housed in groups of 10 animals per polypropylene cages (200 x $120 \times 300 \mathrm{~mm})$, and the rats were housed in pairs in standard cages (Cage 1291H Eurostandard Type III H, $425 \times 266 \times 185 \mathrm{~mm}$, Tecniplast, Italy). All animals were housed in a temperature-controlled room $\left(23 \pm 2{ }^{\circ} \mathrm{C}\right)$ with a 12/12-h light-dark cycle (lights on 6:00 am./lights off 6:00 pm.) with free access to tap water and standard food. The bedding material for rats (Tapvei Estonia OÜ) was made of wood chips with access to tunnel shelter, nesting material, and a wooden stick. For mice, cages were lined with wood shavings without enrichment material in the cages. Female and male animals were allocated in different rooms to avoid interference in the behavioural results.

The Ethics Committee approved the experimental protocols for the Use of Animals from the School of Pharmaceutical Sciences of Ribeirão Preto - USP (Protocol number: 17.1.537.60.6) and the Danish Animal Experiments Inspectorate (Protocol number: 2016150201-001105). The experimental procedures were conducted following the National Council for Control of Animal Experimentation (CONCEA, Brazil) and European Community Council Directive 2010/63/EU. All behavioural experiments were conducted between 9:00 am and 1:00 pm.

\subsection{Drugs}

Synthetic Cannabidiol (CBD; Prati-Donaduzzi, Brazil; Doses: 3, 10 and 30 $\mathrm{mg} / 10 \mathrm{~mL} / \mathrm{kg}$ intraperitoneal (i.p.)) stored at $4^{\circ} \mathrm{C}$ and protected from light, diluted with sterile saline and $2 \%$ polysorbate 80 (Tween ${ }^{\circledR} 80$; Synth, Brazil) for mice [24-26], or synthetic CBD (THC-Pharma, Germany; Doses: 10, 30 and $60 \mathrm{mg} / \mathrm{kg} / 2 \mathrm{~mL}$ i.p.) diluted with sterile saline and 3\% polysorbate 80 (Tween ${ }^{\circledR} 80$; Sigma-Aldrich, USA) for systemic administration in FSL rats [24]. S-Ketamine hydrochloride (Pfizer Ltda, Denmark; Doses: 10, 15 and $20 \mathrm{mg} / \mathrm{kg} / 2 \mathrm{~mL}$ i.p.) stored at $4^{\circ} \mathrm{C}$, was dissolved in sterile saline [24,89] and imipramine hydrochloride (IMIP; Abcam, USA; Dose: $20 \mathrm{mg} / \mathrm{kg} / 10 \mathrm{~mL}$ ), stored at $4^{\circ} \mathrm{C}$ and diluted in sterile saline [90]. The vehicle (VEH) group received CBD vehicle injections. All the drugs were freshly prepared before the experiment. The animals received the treatment randomly by writing treatment of pieces of paper, folding them, mixing, and then drawing one by one for each animal [91].

4.3. Methods and Experimental Design

4.3.1. Mice

4.3.1.1. Experiments 1 and 2 - CBD effects in male and female mice exposed to EPM and TST. 
The elevated plus-maze (EPM) and the tail suspension tests (TST) were conducted to investigate the anxiolytic and antidepressant-related behaviours in mice. The EPM was performed as previously described [27,92]. The apparatus is a plus-shaped maze made of wood and consists of 2 equals enclosed arms (EA; $30 \mathrm{~cm} \times 6 \mathrm{~cm}$; surrounded by walls 15 $\mathrm{cm}$ high) disposed perpendicularly to a 2 equals open arms (OA; $30 \mathrm{~cm} \times 6 \mathrm{~cm}$ ). The animals were placed in the center of the equipment facing one EA and freely exploring the maze for 5 minutes. The OA entries, time, and percentage of time spent in the OA were analyzed. Also, EA entries were assessed as an exploratory behaviour, as described in $[87,92]$.

In the TST, the animal is suspended $60 \mathrm{~cm}$ above the floor with the adhesive tape placed $1 \mathrm{~cm}$ at the tip of the tail on the experimentation table for 6 minutes [84,93]. Moreover, a plastic cylinder tubing (40 mm length; $16 \mathrm{~mm}$ diameter) was placed around the animal tail to prevent tail climbing behaviour, as described previously [94].

Thirty minutes after the habituation period in the experimental room, the mice received the intraperitoneal injection with $\operatorname{VEH}, \operatorname{IMIP}$, or $\operatorname{CBD}(3,10$, and $30 \mathrm{mg} / \mathrm{kg})$. Thirty minutes later, the animals were exposed to the EPM (5 min) and TST (6 min). To avoid interference in the behavioural response in the tests, the experiment carried out with the females was performed independently and on different days of male animals. Besides, the female reproductive cycle status was not taken into account [95].

Independent experiments were carried out for Swiss and C57BL/6 mice for each sex (a total of four independent experiments).

\subsubsection{Flinders Sensitive Line (FSL) rats}

4.3.2.1. Experiment 3 - CBD effect 1 and 2 hours before OFT/FST in male FSL rats.

To assess whether CBD produced an antidepressant-like effect 1 or 2 hours after the injection, the rats received an i.p. injection with $\mathrm{VEH}$, ketamine $(15 \mathrm{mg} / \mathrm{kg})$, or CBD (10, 30 , and $60 \mathrm{mg} / \mathrm{kg}$ ). After 50 minutes or $1 \mathrm{~h} 50$ minutes, the animals were exposed to the OFT (5 minutes) and, immediately after, they were submitted to the FST (5 minutes). The FST was performed, as previously described [24,96]. The FSL and FRL rats were exposed to a 10 minutes test in a Perspex cylinder (height $60 \mathrm{~cm}$, diameter $24 \mathrm{~cm}$ ) filled with tap water at $24 \pm 1^{\circ} \mathrm{C}$, up to $40 \mathrm{~cm}$ height, and the immobility time was measured in the first 5 minutes [24].

To analyze the unspecific change in the locomotor activity produced by the drug treatment open field test (OFT) was performed, as previously described [97]. Immediately before the test in the FST (see below), the rats were submitted individually to an open field square $(100 \mathrm{~cm} \times 100 \mathrm{~cm})$ for 5 minutes. The light intensity was 40 lux at the centre of the arena. The total distance travelled (meter; $\mathrm{m}$ ) was subsequently analyzed using EthoVision ${ }^{\circledR}$ XT14 (Noldus Information Technology, The Netherlands).

In addition, the FSL and FRL rats were handled for 3-5 minutes during three consecutive days before the experiment to habituate the animals to the experimenter and minimize stress caused by manipulation.

4.3.2.2. Experiment 4 - Dose-response curves ketamine in female FSL rats exposed to OFT/FST.

A dose-response curve with ketamine was conducted to determine the effective dose that produced antidepressant-like effects in female FSL rats. For this purpose, one hour after the habituation in the experimental room, the female FRL rats received systemic treatment with VEH (sterile saline), and female FSL rats were treated with VEH or ketamine $(10,15$, and $20 \mathrm{mg} / \mathrm{kg}$ i.p.). Fifty minutes later, the rats were submitted to OFT (5 $\mathrm{min}$ ) and FST (10 $\mathrm{min})$, as previously described. The rat reproductive cycle status was not considered, as it was earlier shown not to affect immobility $[83,98]$. 
4.3.2.3. Experiment $5-$ CBD effect 1 and 2 hours before OFT/FST in female FSL rats.

A similar design described in Experiment 3 was used for females, except that S-ketamine was $20 \mathrm{mg} / \mathrm{kg}$. To avoid interference in the behavioural response in the tests, the experiment carried out with females was conducted independently and on different days than the male. The rat reproductive cycle status was not considered $[83,98]$.

\subsection{Data analysis}

A three-way analysis of variance (ANOVA) was performed to examine the data from mice (Swiss and C57BL/6) and FSL/FRL rats on the parameters evaluated in the behavioural tests, TST, EPM, FST and OFT, in which treatment, sex, strain, and time as an independent factor and immobility time, total distance travelled, OA percentage of spent time and spent time, OA and EA entries as a dependent factor. Significant effects of the strain and in the interaction (treatment vs strain), we performed an independent two-way ANOVA to evaluate the treatment and sex effect in each mice strain, Swiss and C57BL/6. In sequence, significant effect on the treatment and in the interaction (sex vs treatment), we performed one-way ANOVA on each sex to compare the treatment effect on immobility. However, for FSL rats, significant effects of the interaction (treatment vs sex vs time), we performed the following tests: i) Student's t-test, to compare the results between the rat strain, FRL and FSL vehicle-treated groups; ii) One-way ANOVA test followed by Dunnett post hoc test to compare differences between FSL-VEH and FSL-ketamine or FSLCBD and mice treated groups (VEH, IMIP, and CBD). When the variances between the groups were not homogenous, Mann-Whitney (for comparisons between FSL and FRL vehicle-treated groups) or Kruskal-Wallis followed by Dunn's post hoc test (to compare between FSL treated with VEH, ketamine, and CBD and treated mice) was applied. Significant outliers were removed from the statistical analysis through Outlier calculator GraphPad Software (Online version, 2021; GraphPad Software Inc., San Diego, CA, USA). The outliers were the following: male and female FSL rats: 1 rat/sex; female C57BL/6 and male Swiss mice: 5 animals/strain; Male C57BL/6 and female Swiss mice: 3 animals/strain. We calculated and reported the effect size of data from TST and FST using G*Power [99]. Results in the graphs are expressed as the mean \pm standard error of the mean (SEM). A significant difference between groups was considered when $p \leq 0.05$. The $p$-value between 0.05 and 0.1 was considered a statistical trend [100]. Statistical analyses were performed using GraphPad Prism 8.0 (GraphPad Software Inc., San Diego, CA, USA) and SPSS software (version 20.0), and the graphs were created using GraphPad Prism 8.0 (GraphPad Software Inc., San Diego, CA, USA). The raw data are published on FigShare [101-106].

\section{Conclusions}

In conclusion, our findings point out that sex, animal strain, species, and injection time may affect the behavioural response induced by CBD in rodents submitted to animal models of depression. For mice, CBD produced an antidepressant-like effect only in male Swiss mice and no effect in female Swiss mice and both sexes of C57BL/6 mice. Notably, in female FSL rats, CBD produced an antidepressant effect 2 hours post-injection and tended to induce a depressive-like effect at 1 hour. Although, for male FSL, CBD tended to cause an antidepressant at 1 hour and lacked sustained effect ( 2 hours). Therefore, these findings indicate that it is necessary to consider selected sex, animal strain and species, compound chemistry, exposure, and behavioural test when evaluating novel drugs for depression.

Author Contributions: Conceptualization, G.S., S.J. and G.W; methodology, G.S; M.C.G. and A.E.; formal analysis, G.S. and F.S.G.; investigation, G.S; M.C.G. and A.E; writing-original draft preparation, G.S.; writing - review and editing, M.C.G; A.E.; S.J; G.W and F.S.G.; supervision, S.J. and 
G.W.; project administration, S.J. and G.W.; funding acquisition, S.J. and G.W. All authors have read and agreed to the published version of the manuscript.

Funding: GS acknowledges grant support from FAPESP (Grant Nr. 2017/26815-1 and 2018/12119-6) and CNPq (Grant Nr. 141585/2016-1). MCG is thankful to the CNPq for the fellowship for PIBIC. GW is grateful to Independent Research Fund Denmark (grant 8020-00310B), Aarhus University Research Foundation, Denmark (AU-IDEAS initiative (eMOOD)), and EU Horizon 2020 (ExEDE). SJ has received funding from the AIAS-COFUND II fellowship program supported by the Marie Skłodowska-Curie actions under the European Union's Horizon 2020 (Grant agreement no 754513) Aarhus University Research Foundation. SJ is thankful to the CNPq for fellowships for productivity in research (304780/2018-9).

Institutional Review Board Statement: The study was conducted according to the guidelines of the Declaration of Helsinki, and approved by the Local Ethics Committee for the Use of Animals from the School of Pharmaceutical Sciences of Ribeirão Preto - USP (Protocol number: 17.1.537.60.6 and approval 07/10/2019) and the Danish Animal Experiments Inspectorate (Protocol number: 2016150201-001105 and approval 12/23/2016).

Data Availability Statement: The data presented in this study are openly available in FigShare at [https://doi.org/10.6084/m9.figshare.16583408.v1; https://doi.org/10.6084/m9.figshare.16583402.v1; https://doi.org/10.6084/m9.figshare.16583408.v1; https://doi.org/10.6084/m9.figshare.16583417.v1; https://doi.org/10.6084/m9.figshare.16589687.v1; https://doi.org/10.6084/m9.figshare.16589696.v1], reference number [101-106].

Acknowledgements: The authors acknowledge Miriam Contin Melo and Flávia Fiacadori Salata for their helpful technical assistance.

Conflicts of Interest: The authors have no competing interests to declare. GW reported having received research support/lecture/consultancy fees from H. Lundbeck A/S, Servier SA, AstraZeneca AB, Eli Lilly A/S, Sun Pharma Pty Ltd., Pfizer, Inc., Shire A/S, HB Pharma A/S, Arla Foods Amba., Janssen Pharma A/S, and Mundipharma International, Ltd. All other authors declare no conflicts of interest. The funders had no role in the study's design, in the collection, analyses, or interpretation of data, in the writing of the manuscript, or in the decision to publish the results. FSG is a coinventor (Mechoulam R, JC, Guimaraes FS, AZ, JH, Breuer A) of the patent "Fluorinated CBD compounds, compositions and uses thereof. Pub. No.: WO/2014/108899. International Application No.: PCT/IL2014/050023" Def. US no. Reg. 62193296; 29/07/2015; INPI on 19/08/2015 (BR1120150164927). The University of São Paulo has licensed the patent to Phytecs Pharm (USP Resolution No. 15.1.130002.1.1). The University of São Paulo has an agreement with Prati-Donaduzzi (Toledo, Brazil) to "develop a pharmaceutical product containing synthetic cannabidiol and prove its safety and therapeutic efficacy in the treatment of epilepsy, schizophrenia, Parkinson's disease, and anxiety disorders. The funders had no role in the design of the study; in the collection, analyses, or interpretation of data; in the writing of the manuscript, or in the decision to publish the results

\section{References}

1. APA Diagnostic and statictical manual of mental disorders; 2013; ISBN 9780890425541.

2. WHO Depression and other common mental disorders: Global Health Estimates; 2017;

3. WHO WHO I Investing in treatment for depression and anxiety leads to fourfold return. Who 2017, 1-3.

4. Hasin, D.S.; Sarvet, A.L.; Meyers, J.L.; Saha, T.D.; Ruan, W.J.; Stohl, M.; Grant, B.F. Epidemiology of adult DSM-5 major depressive disorder and its specifiers in the United States. JAMA Psychiatry 2018, 75, 336-346, doi:10.1001/jamapsychiatry.2017.4602.

5. Kessler, R.; Bromet, E. The epidemiology of depression across cultures. Annu. Rev. Public Heal. 2013, 34, 119-138, doi:10.1146/annurev-publhealth-031912-114409.The.

6. Chisholm, D.; Sweeny, K.; Sheehan, P.; Rasmussen, B.; Smit, F.; Cuijpers, P.; Saxena, S. Scaling-up treatment of depression and anxiety: A global return on investment analysis. The Lancet Psychiatry 2016, 3, 415-424, doi:10.1016/S2215-0366(16)300244.

7. Olesen, J.; Gustavsson, A.; Svensson, M.; Wittchen, H.U.; Jönsson, B. The economic cost of brain disorders in Europe. Eur. J. 
Neurol. 2012, 19, 155-162, doi:10.1111/j.1468-1331.2011.03590.x.

8. Beery, A.K.; Zucker, I. Sex bias in neuroscience and biomedical research. Neurosci Biobehav Rev 2011, 35, 565-572, doi:10.1038/jid.2014.371.

9. Herzog, D.P.; Wegener, G.; Lieb, K.; Müller, M.B.; Treccani, G. Decoding the mechanism of action of rapid-acting antidepressant treatment strategies: Does gender matter? Int. J. Mol. Sci. 2019, 20, doi:10.3390/ijms20040949.

10. Will, T.R.; Proaño, S.B.; Thomas, A.M.; Kunz, L.M.; Thompson, K.C.; Ginnari, L.A.; Jones, C.H.; Lucas, S.C.; Reavis, E.M.; Dorris, D.M.; et al. Problems and progress regarding sex bias and omission in neuroscience research. eNeuro 2017, 4, 1-10, doi:10.1523/ENEURO.0278-17.2017.

11. Zakiniaeiz, Y.; Cosgrove, K.P.; Potenza, M.N.; Mazure, C.M. Balance of the sexes: Addressing sex differences in preclinical research. Yale J. Biol. Med. 2016, 89, 255-259.

12. Karp, N.A.; Reavey, N. Sex bias in preclinical research and an exploration of how to change the status quo. Br. J. Pharmacol. 2019, 176, 4107-4118, doi:10.1111/bph.14539.

13. Lee, S.K. Sex as an important biological variable in biomedical research. BMB Rep. 2018, 51, 167-173, doi:10.5483/BMBRep.2018.51.4.034.

14. Adams, R.; Hunt, M.; Clark, J.H. Structure of Cannabidiol, a Product Isolated from the Marihuana Extract of Minnesota Wild Hemp. I. J. Am. Chem. Soc. 1940, 62, 196-200, doi:10.1021/ja01858a058.

15. Perez-Reyes, M.; Timmons, M.C.; Davis, K.H.; Wall, E.M. A comparison of the pharmacological activity in man of intravenously administered $\Delta$ 9- Tetrahydrocannabinol, cannabinol, and cannabidiol. Experientia 1973, 29, $1368-1369$.

16. Silote, G.P.; Sartim, A.; Sales, A.; Eskelund, A.; Guimarães, F.S. Emerging evidence for the antidepressant effect of cannabidiol and the underlying molecular mechanisms. J. Chem. Neuroanat. 2019, 98, 104-116, doi:10.1016/j.jchemneu.2019.04.006.

17. Vitale, R.M.; Iannotti, F.A.; Amodeo, P. The (Poly)pharmacology of cannabidiol in neurological and neuropsychiatric disorders: Molecular mechanisms and targets. Int. J. Mol. Sci. 2021, 22, doi:10.3390/ijms22094876.

18. Pisanti, S.; Malfitano, A.M.; Ciaglia, E.; Lamberti, A.; Ranieri, R.; Cuomo, G.; Abate, M.; Faggiana, G.; Proto, M.C.; Fiore, D.; et al. Cannabidiol: State of the art and new challenges for therapeutic applications. Pharmacol. Ther. 2017, 175, 133-150, doi:10.1016/j.pharmthera.2017.02.041.

19. Blessing, E.M.; Steenkamp, M.M.; Manzanares, J.; Marmar, C.R. Cannabidiol as a Potential Treatment for Anxiety Disorders. Neurotherapeutics 2015, 12, 825-836, doi:10.1007/s13311-015-0387-1.

20. Bonaccorso, S.; Ricciardi, A.; Zangani, C.; Chiappini, S.; Schifano, F. Cannabidiol (CBD) use in psychiatric disorders: A systematic review. Neurotoxicology 2019, 74, 282-298, doi:10.1016/j.neuro.2019.08.002.

21. Zuardi, A.W.; Rodrigues, N.P.; Silva, A.L.; Bernardo, S.A.; Hallak, J.E.C.; Guimarães, F.S.; Crippa, J.A.S. Inverted U-shaped dose-response curve of the anxiolytic effect of cannabidiol during public speaking in real life. Front. Pharmacol. 2017, 8, 1-9, doi:10.3389/fphar.2017.00259.

22. El-Alfy, A.T.; Ivey, K.; Robinson, K.; Ahmed, S.; Radwan, M.; Slade, D.; Khan, I.; ElSohly, M.; Ross, S. Antidepressant-like effect of delta9-tetrahydrocannabinol and other cannabinoids isolated from Cannabis sativa L. Pharmacol. Biochem. Behav. 2010, 95, 434-42, doi:10.1016/j.pbb.2010.03.004.

23. Réus, G.Z.; Stringari, R.B.; Ribeiro, K.F.; Luft, T.; Abelaira, H.M.; Fries, G.R.; Aguiar, B.W.; Kapczinski, F.; Hallak, J.E.; Zuardi, A.W.; et al. Administration of cannabidiol and imipramine induces antidepressant-like effects in the forced swimming test and increases brain-derived neurotrophic factor levels in the rat amygdala. Acta Neuropsychiatr. 2011, 23, 241-248, doi:10.1111/j.1601-5215.2011.00579.x.

24. Sales, A.J.; Fogaça, M. V.; Sartim, A.G.; Pereira, V.S.; Wegener, G.; Guimarães, F.S.; Joca, S.R.L. Cannabidiol Induces Rapid and Sustained Antidepressant-Like Effects Through Increased BDNF Signaling and Synaptogenesis in the Prefrontal Cortex. Mol. Neurobiol. 2018, 1-12, doi:10.1007/s12035-018-1143-4. 
25. Sales, A.J.; Crestani, C.C.; Guimarães, F.S.; Joca, S.R.L. Antidepressant-like effect induced by Cannabidiol is dependent on brain serotonin levels. Prog. Neuro-Psychopharmacology Biol. Psychiatry 2018, 86, 255-261, doi:10.1016/j.pnpbp.2018.06.002.

26. Zanelati, T. V.; Biojone, C.; Moreira, F. a.; Guimar??es, F.S.; Joca, S.R.L. Antidepressant-like effects of cannabidiol in mice: Possible involvement of 5-HT 1A receptors. Br. J. Pharmacol. 2010, 159, 122-128, doi:10.1111/j.1476-5381.2009.00521.x.

27. Schiavon, A.P.; Bonato, J.M.; Milani, H.; Guimarães, F.S.; Weffort de Oliveira, R.M. Influence of single and repeated cannabidiol administration on emotional behavior and markers of cell proliferation and neurogenesis in non-stressed mice. Prog. Neuro-Psychopharmacology Biol. Psychiatry 2016, 64, 27-34, doi:10.1016/j.pnpbp.2015.06.017.

28. Linge, R.; Jiménez-Sánchez, L.; Campa, L.; Pilar-Cuéllar, F.; Vidal, R.; Pazos, A.; Adell, A.; Díaz, Á. Cannabidiol induces rapid-acting antidepressant-like effects and enhances cortical 5-HT/glutamate neurotransmission: role of 5-HT1A receptors. Neuropharmacology 2016, 103, 16-26, doi:10.1016/j.neuropharm.2015.12.017.

29. Xu, C.; Chang, T.; Du, Y.; Yu, C.; Tan, X.; Li, X. Pharmacokinetics of oral and intravenous cannabidiol and its antidepressantlike e ff ects in chronic mild stress mouse model. Environ. Toxicol. Pharmacol. 2019, 70, 103202, doi:10.1016/j.etap.2019.103202.

30. Gáll, Z.; Farkas, S.; Albert, Á.; Ferencz, E.; Vancea, S.; Urkon, M.; Kolcsár, M. Effects of chronic cannabidiol treatment in the rat chronic unpredictable mild stress model of depression. Biomolecules 2020, 10, 1-16, doi:10.3390/biom10050801.

31. Shoval, G.; Shbiro, L.; Hershkovitz, L.; Hazut, N.; Zalsman, G.; Mechoulam, R.; Weller, A. Prohedonic effect of cannabidiol in a rat model of depression. Neuropsychobiology 2016, 73, 123-129, doi:10.1159/000443890.

32. Shbiro, L.; Hen-shoval, D.; Hazut, N.; Rapps, K.; Dar, S.; Zalsman, G.; Mechoulam, R.; Weller, A.; Shoval, G. Effects of cannabidiol in males and females in two different rat models of depression. Physiol. Behav. 2019, 201, 59-63, doi:10.1016/j.physbeh.2018.12.019.

33. Bambico, F.R.; Katz, N.; Debonnel, G.; Gobbi, G. Cannabinoids elicit antidepressant-like behavior and activate serotonergic neurons through the medial prefrontal cortex. J. Neurosci. 2007, 27, 11700-11711, doi:10.1523/JNEUROSCI.1636-07.2007.

34. Kirkedal, C.; Wegener, G.; Moreira, F.; Joca, S.R.L.; Liebenberg, N. A dual inhibitor of FAAH and TRPV1 channels shows dose-dependent effect on depression-like behaviour in rats. Acta Neuropsychiatr. 2017, 29, 324-329, doi:10.1017/neu.2016.68.

35. An, X.; Zou, J.; Wu, R.; Yang, Y.; Tai, F. Strain and Sex Differences in Anxiety-Like and Social Behaviors in C57BL / 6J and BALB / cJ Mice. Exp. Anim. 2011, 60, 111-123.

36. Bai, F.; Li, X.; Clay, M.; Lindstrom, T.; Skolnick, P. Intra- and interstrain differences in models of "behavioral despair." Pharmacol. Biochem. Behav. 2001, 70, 187-192, doi:10.1016/S0091-3057(01)00599-8.

37. David, D.J.P.; Renard, C.E.; Jolliet, P.; Hascoët, M.; Bourin, M. Antidepressant-like effects in various mice strains in the forced swimming test. Psychopharmacology (Berl). 2003, 166, 373-382, doi:10.1007/s00213-002-1335-4.

38. Liu, X.; Gershenfeld, H.K. Genetic differences in the tail-suspension test and its relationship to imipramine response among 11 inbred strains of mice. Biol. Psychiatry 2001, 49, 575-581, doi:10.1016/S0006-3223(00)01028-3.

39. Marchette, R.C.N.; Bicca, M.A.; Santos, E.C. da S.; de Lima, T.C.M. Distinctive stress sensitivity and anxiety-like behavior in female mice: Strain differences matter. Neurobiol. Stress 2018, 9, 55-63, doi:10.1016/j.ynstr.2018.08.002.

40. Ripoll, N.; Joseph, D.; David, P.; Dailly, E.; Hascoët, M.; Bourin, M. Antidepressant-like effects in various mice strains in the tail suspension test. Behav. Brain Res. 2003, 143, 193-200, doi:10.1016/S0166-4328(03)00034-2.

41. Võikar, V.; Kõks, S.; Vasar, E.; Rauvala, H. Strain and gender differences in the behavior of mouse lines commonly used in transgenic studies. Physiol. Behav. 2001, 72, 271-281.

42. Porsolt, R.D.; Bertin, A.; Jalfre, M. "Behavioural despair" in rats and mice: Strain differences and the effects of imipramine. Eur. J. Pharmacol. 1978, 51, 291-294, doi:10.1016/0014-2999(78)90414-4.

43. Liu, X.; Gershenfeld, H.K. An exploratory factor analysis of the Tail Suspension Test in 12 inbred strains of mice and an F2 intercross. Brain Res. Bull. 2003, 60, 223-231, doi:10.1016/S0361-9230(03)00033-9.

44. Sales, A.J.; Guimarães, F.S.; Joca, S.R.L. CBD modulates DNA methylation in the prefrontal cortex and hippocampus of mice 
exposed to forced swim. Behav. Brain Res. 2020, 388, 112627, doi:10.1016/j.bbr.2020.112627.

45. Campos, A.C.; Ortega, Z.; Palazuelos, J.; Fogaca, M. V; Aguiar, D.C.; Diaz-Alonso, J.; Ortega-Gutierrez, S.; Vazquez-Villa, H.; Moreira, F. a; Guzman, M.; et al. The anxiolytic effect of cannabidiol on chronically stressed mice depends on hippocampal neurogenesis: involvement of the endocannabinoid system. Int J Neuropsychopharmacol 2013, 16, 1407-1419, doi:10.1017/S1461145712001502.

46. Fogaça, M. V.; Campos, A.C.; Coelho, L.D.; Duman, R.S.; Guimarães, F.S. The anxiolytic effects of cannabidiol in chronically stressed mice are mediated by the endocannabinoid system: Role of neurogenesis and dendritic remodeling. Neuropharmacology 2018, 135, 22-33, doi:10.1016/j.neuropharm.2018.03.001.

47. Fernández-Guasti, A.; Olivares-Nazario, M.; Reyes, R.; Martínez-Mota, L. Sex and age differences in the antidepressant-like effect of fluoxetine in the forced swim test. Pharmacol. Biochem. Behav. 2017, 152, 81-89, doi:10.1016/j.pbb.2016.01.011.

48. Franceschelli, A.; Sens, J.; Herchick, S.; Thelen, C.; Pitychoutis, P.M. Sex differences in the rapid and the sustained antidepressant-like effects of ketamine in stress-nai”ve and “'depressed"' mice exposed to chronic mild stress. Neuroscience 2015, 290, 49-60, doi:10.1016/j.neuroscience.2015.01.008.

49. Gómez, M.L.; Martínez-Mota, L.; Estrada-Camarena, E.; Fernández-Guasti, A. Influence of the brain sexual differentiation process on despair and antidepressant-like effect of fluoxetine in the rat forced swim test. Neuroscience 2014, 261, 11-22, doi:10.1016/j.neuroscience.2013.12.035.

50. Simpson, J.; Ryan, C.; Curley, A.; Mulcaire, J.; Kelly, J.P. Sex differences in baseline and drug-induced behavioural responses in classical behavioural tests. Prog. Neuropsychopharmacol. Biol. Psychiatry 2012, 37, 227-236, doi:10.1016/j.pnpbp.2012.02.004.

51. Wright, K.N.; Kabbaj, M. Sex differences in sub-anesthetic ketamine's antidepressant effects and abuse liability. Curr. Opin. Behav. Sci. 2018, 23, 36-41, doi:10.1016/j.cobeha.2018.02.001.

52. Melo, A.; Kokras, N.; Dalla, C.; Ferreira, C.; Ventura-Silva, A.P.; Sousa, N.; Pi i¹/2go, J.M. The positive effect on ketamine as a priming adjuvant in antidepressant treatment. Transl. Psychiatry 2015, 5, 1-10, doi:10.1038/tp.2015.66.

53. Carrier, N.; Kabbaj, M. Sex differences in the antidepressant-like effects of ketamine. Neuropharmacology 2013, 70, 27-34, doi:10.1016/j.neuropharm.2012.12.009.

54. Deiana, S.; Watanabe, A.; Yamasaki, Y.; Amada, N.; Arthur, M.; Fleming, S.; Woodcock, H.; Dorward, P.; Pigliacampo, B.; Close, S.; et al. Plasma and brain pharmacokinetic profile of cannabidiol (CBD), cannabidivarine (CBDV), $\Delta$ 9tetrahydrocannabivarin (THCV) and cannabigerol (CBG) in rats and mice following oral and intraperitoneal administration and CBD action on obsessive-compulsive behav. Psychopharmacology (Berl). 2012, 219, 859-873, doi:10.1007/s00213-011-24150 .

55. de Morais, H.; Chaves, Y.C.; Waltrick, A.P.F.; Jesus, C.H.A.; Genaro, K.; Crippa, J.A.; da Cunha, J.M.; Zanoveli, J.M. Subchronic treatment with cannabidiol but not with URB597 induced a mild antidepressant-like effect in diabetic rats. Neurosci. Lett. 2018, 682, 62-68, doi:10.1016/j.neulet.2018.06.006.

56. Mechoulam, R.; Shvo, Y. The structure of cannabidiol. Tetrahedrom 1963, 19, 2073-2078.

57. Huestis, M.A. Human cannabinoid pharmacokinetics. Chem. Biodivers. 2007, 4, 1770-1804, doi:10.1016/j.pharma.2008.07.006.

58. Turner, P. V.; Brabb, T.; Pekow, C.; Vasbinder, M.A. Administration of substances to laboratory animals: Routes of administration and factors to consider. J. Am. Assoc. Lab. Anim. Sci. 2011, 50, 600-613.

59. Al Shoyaib, A.; Archie, S.R.; Karamyan, V.T. Intraperitoneal Route of Drug Administration: Should it Be Used in Experimental Animal Studies? Pharm. Res. 2020, 37, doi:10.1007/s11095-019-2745-x.

60. Harvey, D.J. Absorption, Distribution, and Biotransformation of the Cannabinoids. Marihuana Med. 1999, 91-103, doi:10.1007/978-1-59259-710-9_10.

61. Grotenhermen, F. Pharmacokinetics and pharmacodynamics of cannabinoids. Clin. Pharmacokinet. 2003, 42, 327-360, doi:10.2165/00003088-200342040-00003. 
62. Lucas, C.J.; Galettis, P.; Schneider, J. The pharmacokinetics and the pharmacodynamics of cannabinoids. Br. J. Clin. Pharmacol. 2018, 84, 2477-2482, doi:10.1111/bcp.13710.

63. McGilveray, I.J. Pharmacokinetics of cannabinoids. Pain Res. Manag. 2005, 10, 15A-22A.

64. Harvey, D.J.; Samara, E.; Mechoulam, R. Comparative metabolism of cannabidiol in dog, rat and man. Pharmacol. Biochem. Behav. 1991, 40, 523-532, doi:10.1016/0091-3057(91)90358-9.

65. Harvey, D.J.; Brown, N.K. Comparative in vitro metabolism of the cannabinoids. Pharmacol. Biochem. Behav. 1991, 40, 533-540, doi:10.1016/0091-3057(91)90359-A.

66. Samara, E.; Bialer, M.; Harvey, D.J. Metabolism of cannabidiol by the rat. Eur. J. Drug Metab. Pharmacokinet. 1991, 16, 305-313, doi:10.1007/BF03189976.

67. Narimatsu, S.; Watanabe, K.; Yamamoto, I.; Yoshimura, H. Sex difference in the oxidative metabolism of Delta9tetrahydrocannabinol in the rat. Biochem. Pharmacol. 1991, 41, 1187-1194.

68. Wiley, J.L.; Burston, J.J. Sex differences in $\delta 9$-tetrahydrocannabinol metabolism and in vivo pharmacology following acute and repeated dosing in adolescent rats. Neurosci. Lett. 2014, 576, 51-55, doi:10.1016/j.neulet.2014.05.057.

69. Kaufman, J.; Charney, D. Comorbidity of mood and anxiety disorders. Depress. Anxiety 2000, 12, 69-76, doi:10.1002/15206394(2000)12:1+<69::AID-DA9>3.0.CO;2-K.

70. Otte, C.; Gold, S.M.; Penninx, B.W.; Pariante, C.M.; Etkin, A.; Fava, M.; Mohr, D.C.; Schatzberg, A.F. Major depressive disorder. Nat. Rev. Dis. Prim. 2016, 2, 1-21, doi:10.1038/nrdp.2016.65.

71. Kasten, C.R.; Zhang, Y.; Boehm, S.L. Acute cannabinoids produce robust anxiety-like and locomotor effects in mice, but longterm consequences are age- And sex-dependent. Front. Behav. Neurosci. 2019, 13, 1-18, doi:10.3389/fnbeh.2019.00032.

72. Long, L.E.; Chesworth, R.; Huang, X.F.; McGregor, I.S.; Arnold, J.C.; Karl, T. A behavioural comparison of acute and chronic 9- tetrahydrocannabinol and cannabidiol in C57BL/6JArc mice. Int. J. Neuropsychopharmacol. 2010, 13, 861-876, doi:10.1017/S1461145709990605.

73. Carrier, N.; Wang, X.; Sun, L.; Lu, X.Y. Sex-specific and estrous cycle-dependent antidepressant-like effects and hippocampal Akt signaling of leptin. Endocrinology 2015, 156, 3695-3705, doi:10.1210/EN.2015-1029.

74. Chou, D.; Peng, H.Y.; Lin, T. Bin; Lai, C.Y.; Hsieh, M.C.; Wen, Y.C.; Lee, A.S.; Wang, H.H.; Yang, P.S.; Chen, G. Den; et al. $(2 \mathrm{R}, 6 \mathrm{R})$-hydroxynorketamine rescues chronic stress-induced depression-like behavior through its actions in the midbrain periaqueductal gray. Neuropharmacology 2018, 139, 1-12, doi:10.1016/j.neuropharm.2018.06.033.

75. Rincón-Cortés, M.; Grace, A.A. Sex-dependent effects of stress on immobility behavior and VTA dopamine neuron activity: Modulation by ketamine. Int. J. Neuropsychopharmacol. 2017, 20, 823-832, doi:10.1093/ijnp/pyx048.

76. Sarkar, A.; Kabbaj, M. Sex differences in effects of ketamine on behavior, spine density and synaptic proteins in socially isolated rats. Biol. Psychiatry 2017, 80, 448-456, doi:10.1016/S2214-109X(16)30265-0.Cost-effectiveness.

77. Tizabi, Y.; Bhatti, B.H.; Manaye, K.F.; Das, J.R.; Akinfiresoye, L. Antidepressant-like effects of low ketamine dose is associated with increased hippocampal AMPA/NMDA receptor density ratio in female Wistar-Kyoto rats. Neuroscience 2012, 213, 7280, doi:10.1016/j.neuroscience.2012.03.052.ANTIDEPRESSANT-LIKE.

78. Ardalan, M.; Elfving, B.; Rafati, A.H.; Mansouri, M.; Zarate, C.A.; Mathe, A.A.; Wegener, G. Rapid effects of S-ketamine on the morphology of hippocampal astrocytes and BDNF serum levels in a sex-dependent manner. Eur. Neuropsychopharmacol. 2020, 1-10, doi:10.1016/j.euroneuro.2020.01.001.

79. Consoli, D.; Fedotova, J.; Micale, V.; Sapronov, N.S.; Drago, F. Stressors affect the response of male and female rats to clomipramine in a model of behavioral despair ( forced swim test ). Eur. J. Pharmacol. 2005, 520, 100-107, doi:10.1016/j.ejphar.2005.08.012.

80. D'Souza, D.; Sadananda, M. Estrous cycle phase-dependent changes in anxiety-and depression-like profiles in the late adolescent Wistar-Kyoto rat. Ann. Neurosci. 2017, 24, 136-145, doi:10.1159/000477151. 
81. Jaric, I.; Rocks, D.; Cham, H.; Herchek, A.; Kundakovic, M. Sex and estrous cycle effects on anxiety- and depression-related phenotypes in a two-hit developmental stress model. Front. Mol. Neurosci. 2019, 12, 1-15, doi:10.3389/fnmol.2019.00074.

82. Lébron-Milad, K.; Tsareva, A.; Ahmed, N.; Milad, M.R. Sex differences and estrous cycle in female rats interact with the effects of fluoxetine treatment on fear extinction. Behav. Brain Res. 2013, 253, 217-222, doi:10.1161/CIRCULATIONAHA.110.956839.

83. Eskelund, A.; Budac, D.P.; Sanchez, C.; Elfving, B.; Wegener, G. FEMALE FLINDERS SENSITIVE LINE RATS SHOW ESTROUS CYCLE-INDEPENDENT DEPRESSION-LIKE BEHAVIOR AND ALTERED TRYPTOPHAN METABOLISM. Neuroscience 2016, 329, 337-348, doi:10.1016/j.neuroscience.2016.05.024.

84. Cryan, J.F.; Mombereau, C.; Vassout, A. The tail suspension test as a model for assessing antidepressant activity: Review of pharmacological and genetic studies in mice. Neurosci. Biobehav. Rev. 2005, 29, 571-625, doi:10.1016/j.neubiorev.2005.03.009.

85. Stukalin, Y.; Lan, A.; Einat, H. Revisiting the validity of the mouse tail suspension test: Systematic review and meta-analysis of the effects of prototypic antidepressants. Neurosci. Biobehav. Rev. 2020, 112, 39-47, doi:10.1016/j.neubiorev.2020.01.034.

86. Griebel, G.; Belzung, C.; Perrault, G.; Sanger, D.J. Differences in anxiety-related behaviours and in sensitivity to diazepam in inbred and outbred strains of mice. Psychopharmacology (Berl). 2000, 148, 164-170.

87. Komada, M.; Takao, K.; Miyakawa, T. Elevated plus maze for mice. J. Vis. Exp. 2008, 1-4, doi:10.3791/1088.

88. Lister, R.G. The use of a plus-maze to measure anxiety in the mouse. Psychohparmacology 1987, 92, 180-185.

89. Liebenberg, N.; Joca, S.; Wegener, G. Nitric oxide involvement in the antidepressant-like effect of ketamine in the Flinders sensitive line rat model of depression. Acta Neuropsychiatr. 2014, 39, 1-7, doi:10.1017/neu.2014.39.

90. Monleon, S.; D\&apos;Aquila, P.; Parra, A.; Simon, V.M.; Brain, P.F.; Willner, P. Attenuation of sucrose consumption in mice by chronic mild stress and its restoration by imipramine. Psychopharmacology (Berl). 1995, 117, 453-457, doi:10.1007/BF02246218.

91. Bespalov, A.; Michel, M.C.; Steckler, T. Good Research Practice in Pharmacology and Biomedicine; 2020; ISBN 9783030336554.

92. Carobrez, A.P.; Bertoglio, L.J. Ethological and temporal analyses of anxiety-like behavior: The elevated plus-maze model 20 years on. Neurosci. Biobehav. Rev. 2005, 29, 1193-1205, doi:10.1016/j.neubiorev.2005.04.017.

93. Sales, A.J.; Biojone, C.; Terceti, M.S.; Guimarães, F.S.; Gomes, M.V.M.; Joca, S.R.L. Antidepressant-like effect induced by systemic and intra-hippocampal administration of DNA methylation inhibitors. Br. J. Pharmacol. 2011, 164, 1711-21, doi:10.1111/j.1476-5381.2011.01489.x.

94. Can, A.; Dao, D.T.; Terrillion, C.E.; Piantadosi, S.C.; Bhat, S.; Gould, T.D. The tail suspension test. J. Vis. Exp. 2011, 2-7, doi:10.3791/3769.

95. Prendergast, B.J.; Onishi, K.G.; Zucker, I. Female mice liberated for inclusion in neuroscience and biomedical research. Neurosci. Biobehav. Rev. 2014, 40, 1-5, doi:10.1016/j.neubiorev.2014.01.001.

96. Ribeiro, D.E.; Müller, H.K.; Elfving, B.; Eskelund, A.; Joca, S.R.L.; Wegener, G. Antidepressant-like effect induced by P2X7 receptor blockade in FSL rats is associated with BDNF signalling activation. J. Psychopharmacol. 2019, 33, 1436-1446, doi:10.1177/0269881119872173.

97. Pereira, V.S.; Joca, S.R.L.; Harvey, B.H.; Elfving, B.; Wegener, G. Esketamine and rapastinel, but not imipramine, have antidepressant-like effect in a treatment-resistant animal model of depression. Acta Neuropsychiatr. 2019, 31, 258-265, doi:10.1017/neu.2019.25.

98. Becker, J.B.; Prendergast, B.J.; Liang, J.W. Female rats are not more variable than male rats: A meta-analysis of neuroscience studies. Biol. Sex Differ. 2016, 7, 1-7, doi:10.1186/s13293-016-0087-5.

99. Faul, F.; Erdfelder, E.; Buchner, A.-G.L. and A. G*Power 3: A felixble statistical power analysis program for the social, behavioral, and biomedical sciences. Behav. Res. Methods 2007, 39, 175-191.

100. Tillmann, S.; Happ, D.F.; Mikkelsen, P.F.; Geisel, J.; Wegener, G.; Obeid, R. Behavioral and metabolic effects of S- 
adenosylmethionine and imipramine in the Flinders Sensitive Line rat model of depression. Behav. Brain Res. 2019, 364, 274280, doi:10.1016/j.bbr.2019.02.011.

101. Silote, G.P.; Gatto, M.C.; Eskelund, A.; Guimarães, F.S.; Wegener, G.; Joca, S. Figure 1. Effects induced by cannabidiol (CBD) in male Swiss mice submitted to tail suspension test and elevated plus-maze 2021.

102. Silote, G.P.; Gatto, M.C.; Eskelund, A.; Guimarães, F.S.; Wegener, G.; Joca, S. Figure 2. Effects induced by cannabidiol (CBD) in female Swiss mice submitted to tail suspension test and elevated plus-maze. 2021.

103. Silote, G.P.; Gatto, M.C.; Eskelund, A.; Guimarães, F.S.; Wegener, G.; Joca, S. Figure 3. Effects induced by cannabidiol (CBD) in male C57BL/6 mice submitted to tail suspension test and elevated plus-maze. 2021.

104. Silote, G.P.; Gatto, M.C.; Eskelund, A.; Guimarães, F.S.; Wegener, G.; Joca, S. Figure 4. Effects induced by cannabidiol (CBD) in female C57BL/6 mice submitted to tail suspension test and elevated plus-maze. 2021.

105. Silote, G.P.; Gatto, M.C.; Eskelund, A.; Guimarães, F.S.; Wegener, G.; Joca, S. Figure 5. Dose-response curve of S-ketamine in female FSL rats submitted to the forced swim and open field tests. 2021.

106. Silote, G.P.; Gatto, M.C.; Eskelund, A.; Guimarães, F.S.; Wegener, G.; Joca, S. Figures 6 and 7 - Effects of cannabidiol (CBD) administered 1 or 2 hours before the forced swim and open field tests in male and female FSL rats. 2021. 